\title{
On the pulling power of ice streams
}

\author{
T. Hughes \\ Department of Geological Sciences and Institute for Quaternary Studies, \\ University of Maine, Orono, Maine 04469-0110, U.S.A.
}

\begin{abstract}
Gravity wants to pull an ice sheet to the center of the Earth, but cannot because the Earth's crust is in the way, so ice is pushed out sideways instead. Or is it? The ice sheet "sees" nothing preventing it from spreading out except air, which is much less massive than ice. Therefore, does not ice rush forward to fill this relative vacuum; does not the relative vacuum suck ice into it, because Nature abhors a vacuum? If so, the ice sheet is not only pulled downward by gravity, it is also pulled outward by the relative vacuum. This pulling outward will be most rapid where the ice sheet encounters least resistance. The least resistance exists along the bed of ice streams, where ice-bed coupling is reduced by a basal water layer, especially if the ice stream becomes afloat and the floating part is relatively unconfined around its perimeter and unpinned to the sea floor. Ice streams are therefore fast currents of ice that develop near the margins of an ice sheet where these conditions exist. Because of these conditions, ice streams pull ice out of ice sheets and have pulling power equal to the longitudinal gravitational pulling force multiplied by the ice-stream velocity. These boundary conditions beneath and beyond ice streams can be quantified by a basal buoyancy factor that provides a life-cycle classification of ice streams into inception, growth, mature, declining and terminal stages, during which ice streams disintegrate the ice sheet. Surface profiles of ice streams are diagnostic of the stage in a life cycle and, hence, of the vitality of the ice sheet.
\end{abstract}

\section{INTRODUCTION}

The best definition of an ice stream still may be the one Henri Bader gave three decades ago: an "ice stream" is something akin to a mountain glacier consisting of a broad accumulation basin and a narrower valley glacier; but a mountain glacier is laterally hemmed in by rock slopes, while the ice stream is contained by slowermoving surrounding ice. The edges of the ice stream are often crevassed, and the surface tends to be concave as the ice is "funnelled" down. Many of the large outlet glaciers in Greenland, particularly in the south, are the narrow outlets of large ice streams which reach back many scores of miles into the ice sheet. The largest ones flowing into Disko Bay have corresponding depressions in the glacier floor. An interesting question is whether the ice stream makes the depression or vice versa; and an interesting hypothesis is that the ice stream, once started, is self-perpetuating because its ice mass, warmed up by heat of internal friction, has a lower viscosity than the surrounding ice (Bader, 1961).

Insights into these ideas may be found in the pulling power of ice streams. As defined here, pulling power is postulated as the ability of an ice stream to reach deep into an ice sheet and pull out the ice. Formally, pulling power $P_{x}$ at some position on an ice stream is the product of the pulling force $F_{x}$ and ice velocity $\bar{u}_{x}$ at that point, both measured horizontally along direction $x$ of flow:

$$
P_{x}=F_{x} \bar{u}_{x}
$$

where $\bar{u}_{x}$ is averaged through an ice column of height $h$ in a flow band of width $w$. For steady-state flow, $\bar{u}_{x}$ is the equilibrium mass-balance velocity $u$.

Analyzing the pulling power of ice streams involved both old and new concepts. These concepts will now be identified.

Gravitational force, $\mathbf{F}_{z}=F_{\mathrm{g}}$. The gravitational force is the product of the mass of ice (a scalar) multiplied by gravity acceleration (a vector directed toward Earth's center), so $\mathbf{F}_{z}$ is a vector vertically downward.

Pulling force, $F_{x}=\mathbf{F}_{\mathrm{P}}$. The pulling force is the product of lithostatic pressure in ice (a scalar) multiplied by the vertical area across which the pressure is relieved (a vector whose length is proportional to the area and whose direction is away from the ice mass), so $\mathbf{F}_{\mathrm{P}}$ is a vector directed horizontally downstream.

Pushing force, $F_{x}=\mathbf{F}_{\mathrm{P}}$. The pushing force is the product of lithostatic pressure in ice (a scalar) multiplied by 
the vertical area across which the pressure is exerted (a vector whose length is proportional to the area and whose direction is toward the ice mass), so $\mathbf{F}_{\mathrm{P}}$ is a vector directed horizontally downstream.

Braking force, $F_{x}=F_{\mathrm{B}}$. Braking forces are either horizontal traction forces or horizontal kinematic forces. A traction braking force is the product of shear stresses $\sigma_{x y}$ and $\sigma_{x z}$ acting against side and basal surfaces of an ice stream, where shear traction exists, and the areas of these traction surfaces. A kinematic braking force is the product of longitudinal deviator stress $\sigma_{x x}^{\prime}$ that causes kinematic straining, and the cross-sectional area affected by kinematic straining. The analyses of sheet flow by Orowan (British Glaciological Society, 1949) and of shelf flow by Weertman (1957a) were classic examples of using traction and kinematic horizontal braking forces, respectively.

Horizontal force balance, $F_{\mathrm{P}}-F_{\mathrm{B}}=0$. The horizontal force balance requires dynamic equilibrium between horizontal force $F_{\mathrm{P}}$, whether pulling or pushing, both of which require gravity acceleration (which appears in the lithostatic pressure), and braking forces $F_{\mathrm{B}}$, whether traction forces or kinematic forces, both of which require horizontal ice velocity (which causes straining).

Pulling stress, $\sigma_{x x}^{\prime}=\frac{1}{2}\left(\sigma_{x x}-\sigma_{z z}\right)$. The pulling stress is an axial deviator stress in the direction of horizontal ice flow. It represents a deficiency of lithostatic pressure in the horizontal $x$-direction of ice flow, creating a relative vacuum in that direction that is filled by inrushing ice. Hence, strain rate $\dot{\epsilon}_{x x}$ is tensile and proportional to pulling stress $\sigma_{x x}^{\prime}$, where $\sigma_{x x}^{\prime}$ is the average difference between the reduced lithostatic stress $\sigma_{x x}$ and the full lithostatic stress $\sigma_{z z}$, both of which are compressive, so that $\sigma_{x x}^{\prime}$ is tensile.

Pulling power, $P_{x}=F_{x} \bar{u}_{x}$. Pulling power is the product of the horizontal pulling force $F_{\mathrm{P}}$ and mean ice velocity $\bar{u}_{x}$. Therefore, pulling power requires both gravity acceleration (which causes the pulling force) and ice velocity (which causes the braking force). Pulling power is a measure of the vitality of an ice stream, which changes during the life cycle of an ice stream as gravitational potential energy (represented by ice elevation) is converted into kinetic energy (represented by ice velocity) as stream flow moves the ice mass horizontally to lower elevations.

Basal buoyancy factor, $\phi=\left(\rho_{\mathrm{W}} d / \rho_{\mathrm{I}} h\right) \phi_{\mathrm{G}}$. The basal buoyancy factor quantifies ice-bed coupling and ice-shelf buttressing, as the two sources of traction and kinematic braking forces that resist the pulling force. Ice-bed coupling is caused by the fraction of basal lithostatic pressure in ice of height $h$ and density $\rho_{\mathrm{I}}$ that is supported by the bed, instead of by the basal hydrostatic pressure for water of depth $d$ and density $\rho_{\mathrm{W}}$. Full ice-bed coupling $(\phi=0)$ occurs when $d=0$. No ice-bed coupling $\left(\phi=\phi_{\mathrm{G}}\right)$ occurs when $d=\left(\rho_{\mathrm{I}} / \rho_{\mathrm{W}}\right) h$. Full basal buoyancy $(\phi=1)$ occurs when an ice stream is not coupled to the bed and not buttressed by an ice shelf $\left(\phi_{\mathrm{G}}=1\right)$. No basal buoyancy $(\phi=0)$ occurs when an ice stream is either fully coupled to the bed $(d=0)$, or fully buttressed by an ice shelf grounded around its entire perime- ter $\left(\phi_{\mathrm{G}}=0\right)$, or both. The pulling force is maximized for full basal buoyancy and is zero for no basal buoyancy. Ice-bed coupling produces traction forces and ice-shelf buttressing produces kinematic forces, both of which constitute the braking force that balances the pulling force.

Background for the concept of pulling power will be presented, followed by an elaboration on the distinction between pushing and pulling, and an elaboration upon ice-bed coupling and ice-shelf buttressing. Then the horizontal force balance is presented for sheet flow, shelf flow and stream flow. Pulling power is then related to four ice-stream surface profiles, (1) with minimal basal buoyancy, (2) with basal buoyancy continuously decreasing upstream, (3) with equilibrium basal buoyancy, and (4) with maximum basal buoyancy. These conditions of basal buoyancy become the basis for postulating a life-cycle classification for ice streams consisting of inception, growth, mature, declining and terminal stages, with the possiblity for rejuvenation at any stage after inception. A way to model the ice-stream life cycle is presented, and driving the life cycle by pulling power is discussed. Next, pulling power is postulated as the mechanism for disintegrating marine ice sheets by its role in down-drawing ice sheets, discerping ice ridges between ice streams, controling the erosive power of ice streams, regulating ice-shelf buttressing, widening ice streams and causing ice streams to surge. Finally, ways to initiate stream flow are discussed, and results for marine ice streams are generalized to include terrestrial ice streams.

\section{Background}

Work related to the pulling power of ice streams dates at least from the old dispute between Lliboutry (1958) and Nye (1958) as to why transverse crevasses open when a glacier enters a narrow valley. Lliboutry (1958, fig. 4) maintained "To open a crevasse we need a strain, not a stress." His analog was a plastic slab being stretched between rolls, such that transverse compression by the rolls causes longitudinal extension that opens pre-existing transverse cracks. Nye (1958, fig. 1) countered, "I say a stress." His analog was a plastic slab cut into blocks and compressed between frictionless parallel plates, the cuts being the pre-existing transverse cracks. Transverse compressive stress exerted by the plates causes longitudinal extensional strain in the slab, but does not open the cracks. "If, however, we apply a (longitudinal) tensile stress ... the whole thing comes apart." Nye (1958) had proposed pulling power as a disintegration mechanism. His analog was for a valley glacier, but it has significance for ice streams in view of the observation by Bader (1961) that "An ice stream is something akin to a mountain glacier (that enters) a narrow valley ...".

Another indication that ice streams pull ice out of ice sheets was the analysis by Weertman (1963) of outlet glaciers draining an ice sheet fringed by mountain ranges. Although his analysis was for convex surface profiles, if it is applied to the concave surface of a marine ice stream on a horizontal bed, the longitudinal strain rate is a maximum across the surface-inflection line at the head of the ice stream and a minimum across the basal grounding line at the foot of the ice stream, so that basal frictional 
heat is conducted to the surface faster at the head than at the foot of the ice stream. Chances for a frozen bed are therefore greater at the head, with stream-flow sliding on a thawed bed pulling sheet flow anchored to a frozen bed.

The ice-stream analysis by Weertman (1974) involves pulling. He considered an ice stream as the transition zone between an ice sheet and an ice shelf in which the down-slope increase in a longitudinal tension stress allows a corresponding reduction of basal shear stress, and thereby produces a concave profile. Hence, concave "necking" of the ice stream is produced by a longitudinal tensile stress, just as are the transverse crevasses analyzed by Nye (1958). A longitudinal tensile stress requires a longitudinal pulling force.

The concave surface profile of West Antarctic ice streams can be interpreted as a "necking" phenomenon that was causing the maximum-slope surface-inflection line at the heads of ice streams to retreat, ultimately collapsing the West Antarctic ice sheet (Hughes, 1973). Necking has been observed directly by Whillans and others (1987) in longitudinal velocity gradients at the head of Ice Stream B (Fig. 1). The conclusion that necking is caused by pulling also emerges in using slip-line theory to represent the transition from sheet flow to stream flow to shelf flow as analogous to plastic material (ice) being successively drawn through a die, compressed between plates and indented by a punch. Representing the sheet flow to stream-flow transition as being analogous to pushing ice through a die (Hughes, 1977, fig. 17) did not explain the great transverse crevasses arcing around the head of Byrd Glacier (Fig. 1) in the zone of converging flow. These crevasses would form if Byrd Glacier was pulling ice out of East Antarctica, and the analog was to ice being pulled through the die (Stuiver and others, 1981, fig. 8-7). This observation was the basis for

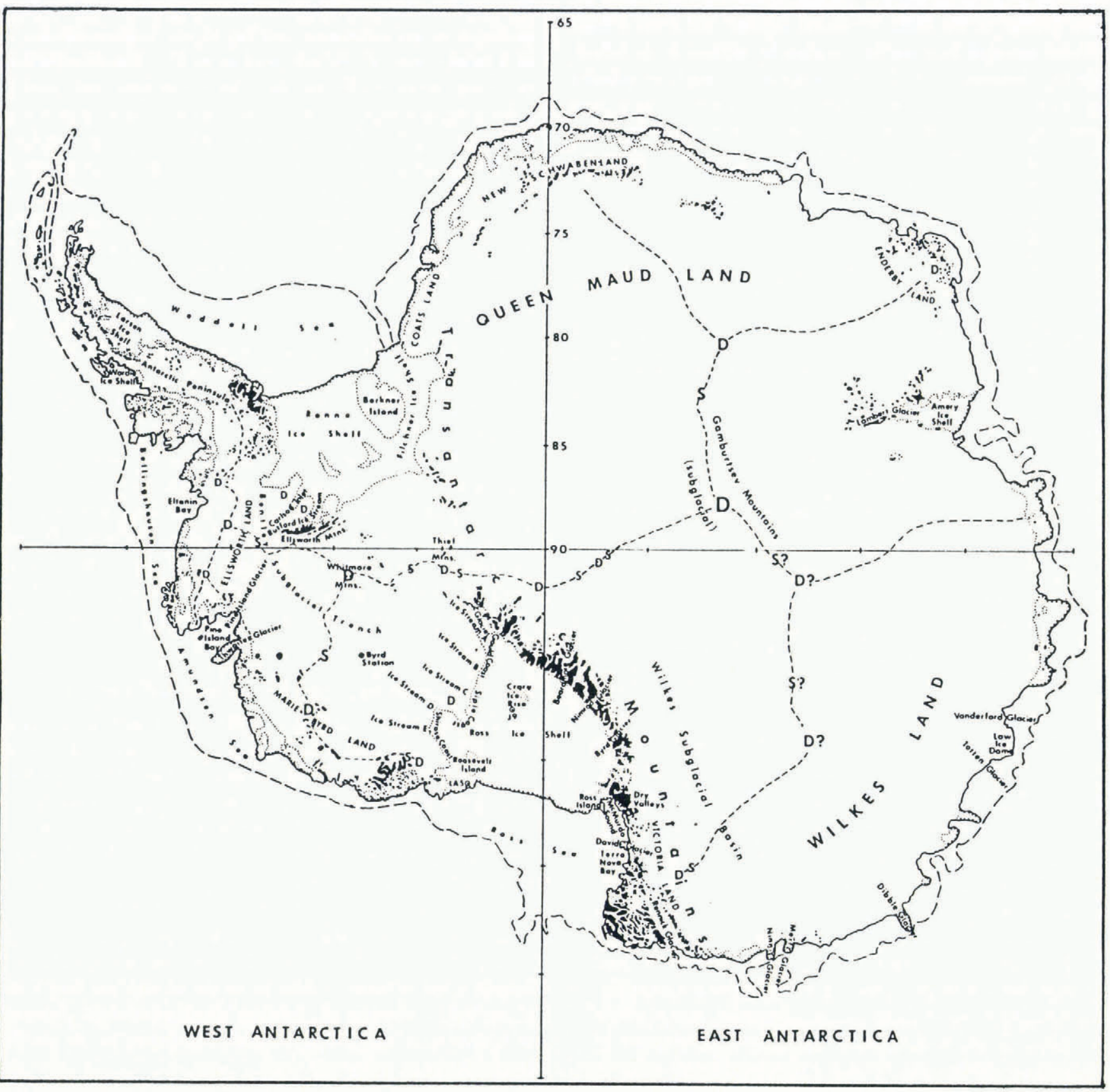

Fig. 1. Location map for selected Antarctic ice streams. 
an early attempt theoretically to quantify the concave profile of ice streams (Hughes, 1981a), and to employ retreating ice streams as the vehicle for collapse of the West Antarctic ice sheet in a computer simulation (Stuiver and others, 1981, fig. 8-7). It can be argued that stream flow also pulls flanking ice into the ice stream, so that the proper analog with a plastic material between parallel plates is that extending plastic flow actively pulls the plates together, rather than extending flow being a passive response to the plates being pushed together.

\section{Pushing versus pulling}

Figure 2 illustrates the distinction between pushing and pulling. Figure 2a shows horizontal spreading of an ice sheet as resulting from vertical lowering caused by a downward pulling force $F_{z}$ equal to the mass of the ice sheet multiplied by gravity acceleration $g$. When the ice sheet is in steady-state equilibrium, the surface profile is unchanged because accumulation rates match the lowering rate and ablation rates match the spreading rate. Vertical pulling by gravity causes horizontal pushing. As seen in Figure 2b, if the ice sheet beyond distance $x$ from the ice margin is removed, it can be replaced by a horizontal pushing force $F_{x}=\left(\frac{1}{2} \rho_{\mathrm{I}} g h\right) w h$, which is resisted by basal traction force $\tau_{0} w x$ over distance $x$ in a flow band of constant width $w$, where $\rho_{\mathrm{I}}$ is ice density, $h$ is ice height at position $x$ and $\tau_{0}$ is basal shear stress over

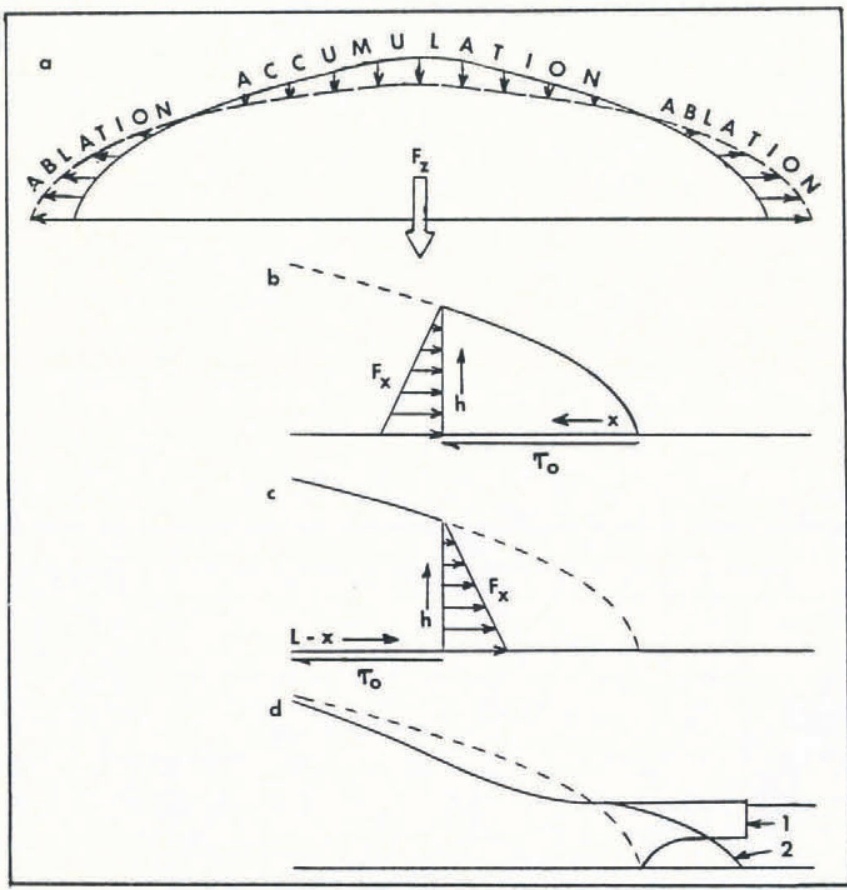

Fig. 2. Producing stream flow from sheet flow. (a) In sheet flow, gravitational pulling force $F_{z}$ deforms the ice sheet from the solid profile to the dashed profile. (b) Inner dashed part of the ice sheet can be replaced by horizontal pushing force $F_{x}$. (c) Outer dashed part of the ice sheet can be replaced by horizontal pulling force $F_{x}$. (d) Horizontal pulling converts the convex surface of sheet flow into the concave surface of stream flow, with stream flow becoming a floating ice shelf in terminus 1 or a grounded ice lobe in terminus 2. distance $x$. Note that $F_{x}$ is directed toward the remaining ice mass, so that by definition $F_{x}=F_{\mathrm{P}}$ is a pushing force. If $\tau_{0}$ is constant, equating the pushing force with the traction force gives $x=\left(\rho_{\mathrm{I}} g / 2 \tau_{0}\right) h^{2}$. This is the convex surface profile of an ice sheet predicted by plasticity theory, in which $\tau_{0}$ is the yield stress.

Horizontal pulling can be induced by removing the ice sheet over distance $x$, so that $F_{x}=\frac{1}{2} \rho_{\mathrm{I}} g w h^{2}$ becomes a pulling force resisted by basal traction force $\tau_{0} w(L-x)$ over distance $L-x$ where $L$ is the length of the flow band from the ice divide to the margin, as shown in Figure 2c. Note that $F_{x}$ is directed away from the remaining ice mass, so that by definition $F_{x}=F_{\mathrm{P}}$ is a pulling force. Pulling extends only to the ice divide because $\tau_{0}$ reverses sign across the ice divide. Equating the forces for constant $\tau_{0}$ gives $L-x=\left(\rho_{\mathrm{I}} g / 2 \tau_{0}\right) h^{2}$ as the distance over which $F_{x}$ is exerted for a given $h$ and $\tau_{0}$ in Figure 2c. With $F_{x}$ a pulling force instead of a pushing force, the ice surface over distance $L-x$ is quickly pulled down by $F_{z}$ as ice is pulled forward by $F_{x}$. A similar result is obtained by not removing the ice sheet over distance $x$ but, instead, having $\tau_{0}$ be large over $L-x$ and small over $x$, which produces the concave surface of stream flow in Figure 2d. An ice stream can end as a floating ice shelf, beneath which $\tau_{0}$ is zero (shown as terminal region 1), or as a grounded ice lobe, beneath which $\tau_{0}$ increases to the ice margin (shown as terminal region 2). A marine ice stream supplies an ice shelf. A terrestrial ice stream supplies an ice lobe. Marine ice streams are the subject of this investigation because predictions can be tested by field studies on the numerous present-day marine ice streams. In Figure 2d, pulling force $F_{\mathrm{P}}$ at distance $x$ from the ice-stream grounding line or the ice-lobe terminus will be net horizontal force $\Delta F_{x}=\frac{1}{2} \rho_{\mathrm{I}} g w h^{2}-\frac{1}{2} \rho_{\mathrm{W}} g w d^{2}$, where $\rho_{\mathrm{W}}$ is water density and $d$ is the depth of water that would produce the hydrostatic pressure of basal meltwater at $x$.

As presented in Figure 2, horizontal force $F_{x}$ is a pushing force for sheet flow and a pulling force for stream flow, both produced by gravity, and both inducing traction forces that resist gravitational motion. Hence, $F_{x}$ will be used to represent gravitational forcing, with $F_{x}=F_{\mathrm{P}}$ causing pushing or pulling, and $F_{\mathrm{B}}$ will represent braking forces caused by stresses that resist pushing or pulling motion.

\section{Ice-bed coupling and ice-shelf buttressing}

As presented in Figure 2, stream flow is generated from sheet flow by reducing ice-bed coupling toward the terminus of a flow band. If that is the case, marine ice streams are the major dynamic links connecting a marine ice sheet with its floating ice shelves, and stream flow is transitional between sheet flow and shelf flow. However, stream flow cannot develop from sheet flow if reduced ice-bed coupling is completely offset by increased iceshelf buttressing. To illustrate this, consider an ice cube in a pan. If water is added to the pan, an ice cube of height $h$ will begin to float in water of depth $d$ when the lithostatic pressure of ice and the hydrostatic pressure of water give the same overburden pressure $\sigma_{0}$ on the bottom of the pan:

$$
\sigma_{0}=\rho_{\mathrm{I}} g h=\rho_{\mathrm{W}} g d
$$


where $\rho_{\mathrm{I}}$ is ice density, $\rho_{\mathrm{W}}$ is water density and $g$ is gravity acceleration. Ice-bed coupling is nil when Equation (2) is satisfied. Now imagine that the ice cube is a large tabular iceberg and the pan is a larger lake. Elimination of ice-bed coupling allows pulling force $F_{\mathrm{P}}$ to spread the iceberg radially, in the manner analyzed by Weertman (1957a), until the iceberg grounds along the shoreline of the lake, thereby producing a braking force $F_{\mathrm{B}}$ that completely cancels $F_{\mathrm{P}}$. Hence, ice-bed coupling is removed in the center of the lake by a gain of basal buoyancy, and ice-shelf buttressing is attained around the perimeter of the lake by a loss of basal buoyancy.

The above considerations suggest that the pulling power of a marine ice stream is controled by basal buoyancy. Pulling power is increased when ice-bed coupling beneath an ice stream is decreased by basal buoyancy. Pulling power is decreased when ice-shelf buttressing beyond an ice stream is increased by a loss of basal buoyancy around the grounded parts of the ice shelf. Both ice-bed coupling and ice-shelf buttressing can therefore be quantified by a basal buoyancy factor $\phi$ that is defined as follows:

$$
\phi=\left(\rho_{\mathrm{W}} d / \rho_{\mathrm{I}} h\right) \phi_{\mathrm{G}}
$$

where basal water would rise to a depth $d$ in ice of height $h$ in imaginary temperate boreholes along length $L_{\mathrm{S}}$ of an ice stream, as shown in Figure 3 , and $\phi_{\mathrm{G}}$ is $\phi$ at the ice-stream grounding line of a floating ice shelf. In determining $\phi$ from Equation (3), variations in $d$ are controled by variations in ice-bed coupling, and variations in $\phi_{\mathrm{G}}$ are controled by variations in ice-shelf buttressing.

Since basal water can exist as a thin film at the icerock interface, can flow in a network of subglacial channels, can be ponded in subglacial lakes and can occupy interstitial pores in subglacial till or sediments, depth $d$ of basal water standing in imaginary temperate boreholes, as employed in Equation (3), is a statistical averaging of all these forms of basal water across width $w$ of the ice stream at a distance $x$ from its grounding line. In particular, it will be assumed that $d=0$ where basal water is a thin film. This assumption is reached by considering a subglacial lake in which bedrock hilltops penetrate temperate basal ice. A thin water film covers the hilltops. If the lake is now drained, the bedrock hills would act like pillars supporting the ceiling of basal ice. Therefore, even though a water film exists on the hilltops, the overburden of ice is supported by bedrock, not basal buoyancy, because bedrock is continuous whereas the water film exists only at the ice-rock interface on hilltops. This fact is incorporated into Equation (3) by setting $d=0$ in imaginary boreholes drilled down to the hilltops, even though the hydrostatic pressure of water in both the film and the lake equals the same lithostatic overburden pressure of ice before the lake was drained, and lake water would rise to a depth $d=\left(\rho_{\mathrm{I}} / \rho_{\mathrm{W}}\right) h$ in a borehole drilled above the lake. Another reason for letting $d=0$ when the water layer is a film over rugged bedrock is that $d$ has meaning for pulling power only insofar as ice-bed coupling resists stream flow. Hence, $d=0$ for all undrowned bedrock projections because these resist stream flow by retaining ice-bed coupling that retards horizontal ice motion. This is the essence of the Weertman (1957b) sliding theory, in which basal



Fig. 3. Pulling forces defined as net horizontal lithostatic and hydrostatic forces acting in a marine flow band of an ice sheet. Horizontal lithostatic and hydrostatic forces pressing against imaginary ice columns are shown for sheet flow (right), stream flow (center) and shelf flow (left), with the flow band having floating length $L_{F}$, grounded length $L$ and streaming length $L_{\mathrm{S}}$. Averaged for the ice column, basal water rises to depth $d$ in imaginary temperate boreholes drilled through the flow band. Four cases analyzed in the text for the ice stream are no buoyancy along $L_{\mathrm{S}}$ (case I), full buoyancy at the basal grounding line decreasing to no buoyancy at the surfaceinflection line (case II), constant buoyancy along $L_{\mathrm{S}}$ (case III) and full buoyancy along $L_{\mathrm{S}}$ (case IV).

water pressure is not involved, only bed roughness which provides traction that retards sliding. This understanding of $d$ can be generalized in Equation (3) by specifying that $d=0$ gives $\phi=0$ for sheet flow with no basal buoyancy, $d=\left(\rho_{\mathrm{I}} / \rho_{\mathrm{W}}\right) h$ gives $\phi=\phi_{\mathrm{G}}$ for shelf flow with full basal buoyancy, and intermediate values of $d$ give $0<\phi<\phi_{\mathrm{G}}$ for stream flow with partial basal buoyancy.

Ice-shelf buttressing of an ice stream is determined by $\phi_{\mathrm{G}}$ in Equation (3), such that $\phi_{\mathrm{G}}=0$ when the ice shelf is grounded around its entire perimeter, $\phi_{\mathrm{G}}=1$ when the ice shelf is grounded only along the ice-stream grounding line, and $0<\phi_{\mathrm{G}}<1$ when the ice shelf occupies an embayment or is pinned by islands and shoals. In Figure 1, examples of $\phi_{\mathrm{G}}=0$ are ice above subglacial lakes near the interior ice dome of Wilkes Land (Oswald 
and Robin, 1973), and the "pseudo ice shelves" of Ice Stream C (Robin and others, 1970); examples of $\phi_{\mathrm{G}}=1$ are the floating ice tongues of Thwaites, David, Ninnis and Mertz Glaciers; and examples of $0<\phi_{\mathrm{G}}<1$ are the Ross and Ronne Ice Shelves.

Refer to Figure 3, for which $d$ changes along an ice stream of length $L_{\mathrm{S}}$ and $\phi_{\mathrm{G}}=1$ for an ice shelf of length $L_{\mathrm{F}}$. Over length $L-L_{\mathrm{S}}$, sheet flow with $\phi=0$ exists when the bed is frozen, or thawed, but with only a basal water film. Over length $L_{\mathrm{S}}$, stream flow with $\phi=0$ exists when basal water is only thick enough to drown bedrock projections up to the controling obstacle size in the Weertman (1975b) theory of basal sliding, and $\phi=$ 1 when basal water saturates basal till or sediments so they are unable to support a basal shear stress; otherwise $0<\phi<1$ in the ice stream, depending on how $d$ varies along $L_{\mathrm{S}}$, where $d$ is statistically averaged for basal water conditions across a given width $w$ of the ice stream.

Ice-bed coupling and ice-shelf buttressing are quantified by $\phi$ to provide a means for assessing the pulling power of ice streams using Equation (1). The plan to be followed consists of:

1. Presenting a force balance for stream flow that reduces to force balances for sheet flow when $\phi=0$ and shelf flow when $\phi=1$.

2. Deriving ice-stream profiles for a range of $\phi$ values and computing pulling power along these profiles for steady-state equilibrium.

3. Classifying ice streams in a hypothetical scheme in which the pulling-power curve is diagnostic of the position of an ice stream in its life cycle.

4. Applying the concept of pulling power to disintegration of marine ice sheets, notably in West Antarctica.

The goal of this plan is to provide numerical models of ice sheets with a parameter $\phi$ that quantifies ice-bed coupling and ice-shelf buttressing for the ice streams that drain the ice sheet. Rapid collapse of marine ice sheets can then be simulated by allowing $\phi$ to represent increases in ice-stream pulling power resulting from uncoupling and unbuttressing.

\section{FORCE BALANCES ALONG A FLOW BAND}

Figure 3 shows an ice sheet flow band of constant width on a horizontal bed. The flow band begins as sheet flow (right) and ends as shelf flow (left), with stream flow (center), being a transition from sheet flow to shelf flow. Constant width and a horizontal bed are specified so the transitional nature of stream flow can be analyzed in its simplest form, without complications introduced by laterally converging or diverging flow and variable bed topography. The origin of rectilinear coordinates is the ice-shelf grounding line, with $x$ horizontal and positive toward the ice divide and $z$ vertical and positive upward. The flow band has floating length $L_{\mathrm{F}}$, and an ice stream of length $L_{\mathrm{S}}$ over grounded length $L$, with $h_{\mathrm{G}}$ being ice height at the grounding line separating shelf flow from stream flow and $h_{\mathrm{S}}$ being ice height at the inflection line separating stream flow from sheet flow.

Force balances are computed for ice columns in the sheet-flow, stream-flow and shelf-flow parts of the flow band. Assumptions are (1) dynamic equilibrium exists, (2) longitudinal gradients in stretching stress are small, and (3) the $T$-term can be neglected (Paterson, 1981, p. 164). Assumption (1) is justified if pulling force $F_{\mathrm{P}}$ is added to braking force $F_{\mathrm{B}}$ such that $F_{\mathrm{P}}+F_{\mathrm{B}}=0$. Assumptions (2) and (3) are reasonable for a flow band of constant width on a horizontal bed (Muszynski, 1987; Muszynski and Birchfield, 1987; Van der Veen, 1987). The pulling force in all cases is merely the expression of Newton's second law, $F_{\mathrm{P}}$ being gravity acceleration acting on the mass of the ice column, with $F_{\mathrm{P}}$ in the horizontal $x$-direction being an average differential pressure exerted on faces of the ice column that are normal to the $x$-direction. The braking force in all cases arises from motion or deformation of the ice column, with $F_{\mathrm{B}}$ consisting of the sum of stresses resisting the motion or deformation multiplied by the area of the ice column upon which these stresses act. None of this is new, but it will now be reviewed for sheet flow and shelf flow, before analyzing stream flow as being transitional between these two.

\section{Force balance for sheet flow}

Pushing force $F_{\mathrm{P}}$ for an ice sheet on a horizontal bed is obtained from the horizontal lithostatic forces shown in Figure 4 (right). A vertical ice column has downslope height $h$ and upslope height $h+\Delta h$ along incremental length $\Delta x$ over which flow-band width $w$ is constant. The pushing force per unit width is the difference between the areas of force triangles 1 and 2, defined as the mean lithostatic pressures acting on the upslope and downslope sides of the ice column, respectively. Therefore, for an ice-sheet flow band of width $w$ :

$$
\begin{aligned}
F_{\mathrm{P}}=- & {\left[\frac{1}{2} \rho_{\mathrm{I}} g(h+\Delta h)\right][w(h+\Delta h)] } \\
& +\left[\frac{1}{2} \rho_{\mathrm{I}} g h\right][w h] \approx-\rho_{\mathrm{I}} g w h \Delta h
\end{aligned}
$$



Fig. 4. Horizontal forces on ice columns having constant width and no side traction. Horizontal gravitational forces per unit width are the areas of triangles 1, 2 and 4, and rectangle 3. Traction force is basal shear stress $\tau_{0}$ times the basal area of the ice column. Pulling force is tensile deviator stress $2 \sigma_{x x}^{\prime}$ times the transverse cross-sectional area on the landward side of the ice column. Following Whillans (1987), the role of basal water pressure can be emphasized by distinguishing lithostatic pressure in triangles 1 and 2, and rectangle 3 from hydrostatic pressure in triangle 4 . 
where the term containing $(\Delta h)^{2}$ can be ignored. Note that $F_{\mathrm{P}}$ is a force gradient, because it increases with ice-thickness change $\Delta h$. Lithostatic pressure $\rho_{\mathrm{I}} g(h+$ $\left.\frac{1}{2} \Delta h\right) \approx \rho_{\mathrm{I}} g h$ pushes against area $w \Delta h$ to produce $F_{\mathrm{P}}$.

Pushing gravitational motion induces creep controled by deviator shear stress $\sigma_{x z}$, where $\tau_{0}=\sigma_{x z}$ at $z=0$ is the basal shear stress. Since resistance to creep is provided by basal shear stress $\tau_{0}$ acting on basal area $w \Delta x$, and $\sigma_{x z}=\tau_{0}(1-z / h)$, the braking force is:

$F_{\mathrm{B}}=\tau_{0} w \Delta x=\sigma_{x x} h w \Delta x /(h-z)=\dot{\epsilon}_{x z}^{1 / n} \bar{A} h w \Delta x /(h-z)$

where $\sigma_{x z}$ is expressed in terms of the strain rate $\dot{\epsilon}_{x z}$ of ice in simple shear for the creep law

$$
\dot{\epsilon}_{x z}=\left(\tau^{n-1} / A^{n}\right) \sigma_{x z}=\left(\sigma_{x z} / A\right)^{n}
$$

in which $\tau$ is the effective shear stress, $n$ is a viscoplastic exponent, $A$ is an ice-hardness parameter, $A$ averaged through $h$ is $\bar{A}$ and $\tau=\sigma_{x z}$ for simple shear.

When the ice column is in dynamic equilibrium, $F_{\mathrm{P}}=$ $-F_{\mathrm{B}}$ and (Nye, 1957):

$$
\dot{\epsilon}_{x z}=\left[\rho_{\mathrm{I}} g(h-z) \Delta h / \bar{A} \Delta x\right]^{n}=\left[\tau_{0}(1-z / h) / \bar{A}\right]^{n}
$$

where $\tau_{0}=\rho_{\mathrm{I}} g h \Delta h / \Delta x$ is often called the "driving stress" for an ice sheet. Actually, $\tau_{0}$ is a braking stress that resists ice motion. It takes on the role of a driving stress only when $F_{\mathrm{P}}$ is equated with $F_{\mathrm{B}}$, as only $F_{\mathrm{P}}$ expresses the product of ice mass and gravity acceleration.

\section{Force balance for shelf flow}

Pulling force $F_{\mathrm{P}}$ for an ice shelf having only longitudinal extension and no side traction is obtained from the horizontal lithostatic and hydrostatic forces shown in Figure 4 (left). A vertical ice column has constant height $h$ and width $w$ over incremental length $\Delta x$ and floats at depth $d$ in water. Ice on the side facing the calving front can be replaced by an equivalent mass of water without changing the nature of this boundary, whereas ice facing the grounding line cannot. Hence, horizontal forces on opposite sides are unbalanced, with a net seaward pulling force. The pulling force per unit width is the difference between the areas of force triangles 1 and 4 , defined as the mean lithostatic and hydrostatic pressures acting on the sides of the ice column facing the grounding line and the calving front, respectively, of the ice shelf. Therefore, for an ice-shelf flow band of width $w$ :

$$
\begin{aligned}
F_{\mathrm{P}} & =-\left[\frac{1}{2} \rho_{\mathrm{I}} g h\right][w h]+\left[\frac{1}{2} \rho_{\mathrm{W}} g d\right][w d] \\
& =-\frac{1}{2} \rho_{\mathrm{I}} g w h^{2}\left[1-\left(\rho_{\mathrm{I}} / \rho_{\mathrm{W}}\right)\right]
\end{aligned}
$$

where $d=h\left(\rho_{\mathrm{I}} / \rho_{\mathrm{W}}\right)$ satisfies the buoyancy requirement for floating ice, $\phi=1$ in Equation (3).

Pulling gravitational motion induces creep controled by deviator tensile stress $\sigma_{x x}^{\prime}$, where $\sigma_{x x}^{\prime}=\frac{1}{2}\left(\sigma_{x x}-\sigma_{z z}\right)$ and $\sigma_{x x}-\sigma_{z z}$ is the deviation of longitudinal stress $\sigma_{x x}$ from overburden lithostatic stress $\sigma_{z z}=\rho_{\mathrm{I}} g(z-h)$ in the ice column. Both $\sigma_{x x}$ and $\sigma_{z z}$ are zero at the ice surface, so resistance to creep is provided by average longitudinal tensile stress $\frac{1}{2}\left(\sigma_{x x}-\sigma_{z z}\right)$ acting at distance $h-z$ below the surface on transverse cross-sectional area $w h$, which is constant over length $\Delta x$. Braking force $F_{\mathrm{B}}$ therefore results from $\sigma_{x x}^{\prime}$, which produces kinematic strain rate $\dot{\epsilon}_{x x}$ as follows:

$$
\begin{aligned}
F_{\mathrm{B}} & =\int_{0}^{h}\left(\sigma_{x x}-\sigma_{z z}\right) w \mathrm{~d} z=2 w \int_{0}^{h} \sigma_{x x}^{\prime} \mathrm{d} z \\
& =2 w \dot{\epsilon}_{x x}^{1 / n} \int_{0}^{h} A \mathrm{~d} z=2 w h \bar{A} \dot{\epsilon}_{x x}^{1 / n}
\end{aligned}
$$

where $\sigma_{x x}^{\prime}$ is expressed in terms of the strain rate $\dot{\epsilon}_{x x}$ of ice in longitudinal tension for the creep law:

$$
\dot{\epsilon}_{x x}=\left(\tau^{n-1} / A^{n}\right) \sigma_{x x}^{\prime}=\left(\sigma_{x x}^{\prime} / A\right)^{n}
$$

in which $\dot{\epsilon}_{x x}$ is constant through $h$ over length $\Delta x$ and $\tau=\sigma_{x x}^{\prime}$ for constant $w$.

When the ice column is in dynamic equilibrium, $F_{\mathrm{P}}=$ $-F_{\mathrm{B}}$ and (Weertman, 1957a):

$$
\dot{\epsilon}_{x x}=\left[\rho_{\mathrm{I}} g h\left(1-\rho_{\mathrm{I}} / \rho_{\mathrm{W}}\right) / 4 \bar{A}\right]^{n}=\left[\sigma_{0}\left(1-\rho_{\mathrm{I}} / \rho_{\mathrm{W}}\right) / 4 \bar{A}\right]^{n}
$$

where $\dot{\epsilon}_{x x}=-\dot{\epsilon}_{z z}$ for constant $w$ and volume conservation, and $\sigma_{0}=\rho_{\mathrm{I}} g h$ is the basal lithostatic and hydrostatic pressure.

\section{Force balance for stream flow}

Pulling force $F_{\mathrm{P}}$ for an ice stream having longitudinal extension and both basal and side traction is obtained from the horizontal lithostatic and hydrostatic forces shown in Figure 4 (center). A vertical ice column has downslope height $h$ and upslope height $h+\Delta h$ along incremental length $\Delta x$, over which basal water would rise in temperate boreholes to an average depth $d$ above the bed. The average $d$ is based upon the fractions of the bed in basal area $w \Delta x$ having no buoyancy $(\phi=0)$ and full buoyancy $\left(\phi=\phi_{\mathrm{G}}\right)$. The pulling force per unit width is the area of force triangle 1 minus the combined areas of force triangle 2 , force rectangle 3 and force triangle 4 . Therefore, for an ice stream of width $w$ :

$$
\begin{aligned}
F_{\mathrm{P}}=- & \frac{1}{2} \rho_{\mathrm{I}} g(h+\Delta h) w(h+\Delta h) \\
& +\frac{1}{2} \rho_{\mathrm{I}} g\left[h-d\left(\rho_{\mathrm{W}} / \rho_{\mathrm{I}}\right)\right] w\left[h-d\left(\rho_{\mathrm{W}} / \rho_{\mathrm{I}}\right)\right] \\
& +\rho_{\mathrm{I}} g\left[h-d\left(\rho_{\mathrm{WV}} / \rho_{\mathrm{I}}\right)\right] w d\left(\rho_{\mathrm{W}} / \rho_{\mathrm{I}}\right)+\left(\frac{1}{2} \rho_{\mathrm{W}} g d\right) w d \\
= & -\rho_{\mathrm{I}} g w h \Delta h-\frac{1}{2} \rho_{\mathrm{I}} g w h^{2}\left[1-\left(\rho_{\mathrm{I}} / \rho_{\mathrm{W}}\right)\right] \phi^{2}
\end{aligned}
$$

where $\phi$ is introduced by using Equation (3). Note that Equation (12) for stream flow reduces to Equation (4) for sheet flow when $\phi=0$ and to Equation (8) for shelf flow when $\phi=1$ and $\Delta h=0$ along length $\Delta x$.

In Equation (12), downslope pulling by the first term is partly offset by upslope pushing by the second, third and fourth terms to give a net forward pulling. The first term is the mean lithostatic pressure exerted on column area $w(h+\Delta h)$ to produce the horizontal pulling force per unit width given by the area of triangle 1 in Figure 4. The second term is the mean lithostatic pressure above height $d\left(\rho_{\mathrm{W}} / \rho_{\mathrm{I}}\right)$ exerted on column area $w\left[h-d\left(\rho_{\mathrm{W}} / \rho_{\mathrm{I}}\right)\right]$ above this height to produce the horizontal pushing force per unit width given by the area of triangle 2 in Figure 4. The third term is the lithostatic pressure at height $d\left(\rho_{\mathrm{W}} / \rho_{\mathrm{I}}\right)$ exerted on column area $w d\left(\rho_{\mathrm{W}} / \rho_{\mathrm{I}}\right)$ be- 
low this height to produce the horizontal pushing force per unit width given by the area of rectangle 3 in Figure 4 . The fourth term is the mean hydrostatic pressure below height $d$ exerted on column area $w d$ below this height to produce the horizontal pushing force per unit width given by the area of triangle 4 in Figure 4 .

Notice that the horizontal hydrostatic force per unit width exerted by water, the area of triangle 4 in Figure 4, is shown only on the seaward side of ice columns for which $d>0$ in Figure 3. This is because a marine ice stream and its floating ice-shelf extension interface with water beyond the seaward wide of the ice column, but not the landward side, where only lithostatic forces exist. Hence, any gradient $\partial d / \partial x$ along length $L_{\mathrm{S}}$ of stream flow, as shown in Figure 3, need not be considered in balancing horizontal forces on the ice columns.

That stream flow is transitional between sheet flow and shelf flow is seen in Figure 4. Moving $d\left(\rho_{\mathrm{W}} / \rho_{\mathrm{I}}\right)$ downward increases $\Delta h$ by causing triangle 2 to encroach upon rectangle 3 and triangle 4 until sheet flow occurs at $d\left(\rho_{\mathrm{W}} / \rho_{\mathrm{I}}\right)=0$, reducing Equation (12) to Equation (4) at $\phi=0$. Moving $d\left(\rho_{\mathrm{W}} / \rho_{\mathrm{I}}\right)$ upward decreases $\Delta h$ by causing triangle 4 to encroach upon rectangle 3 and triangle 2 until shelf flow occurs at $d\left(\rho_{\mathrm{W}} / \rho_{\mathrm{I}}\right)=h$, reducing Equation (12) to Equation (8) at $\phi=1$ and $\Delta h=0$.

Pulling gravitational motion induces creep controled by deviator tensile stress $\sigma_{x x}^{\prime}$ along $\Delta x$ and deviator shear stresses $\sigma_{x y}$ and $\sigma_{x z}$ along $w$ and $h$, respectively, with maximum values $\sigma_{x y}=\tau_{\mathrm{S}}$ for side traction and $\sigma_{x z}=\tau_{0}$ for basal traction in the ice stream. Multiplying these deviator stresses by the areas against which they act gives braking force $F_{\mathrm{B}}$. Taking $\bar{h}=h+\frac{1}{2} \Delta h$ as the mean ice height along $\Delta x$ and $\sigma_{x x}^{\prime}=\frac{1}{2}\left(\sigma_{x x}-\sigma_{z z}\right)$, where $\sigma_{x x}-\sigma_{z z}$ is the deviation of longitudinal stress $\sigma_{x x}$ from lithostatic stress $\sigma_{z z}=\rho_{\mathrm{I}} g(z-h)$ in the Robin (1967) analysis:

$$
\begin{aligned}
F_{\mathrm{B}}= & 2 \tau_{\mathrm{S}} \bar{h} \Delta x+\tau_{0} w \Delta x+2\left(\sigma_{x x}^{\prime}+\Delta \sigma_{x x}^{\prime}\right) w(h+\Delta h) \\
= & \left(2 \tau_{\mathrm{S}} h+\tau_{\mathrm{S}} \Delta h+\tau_{0} w\right) \Delta x \\
& +2 w\left(\sigma_{x x}^{\prime} h+\sigma_{x x}^{\prime} \Delta h+h \Delta \sigma_{x x}^{\prime}\right)
\end{aligned}
$$

where $\Delta \sigma_{x x}^{\prime}$ is the change in $\sigma_{x x}^{\prime}$ along $\Delta x$ and the term containing $\Delta \sigma_{x x}^{\prime} \Delta h$ can be ignored.

When the ice column is in dynamic equilibrium, $\vec{F}_{\mathrm{P}}=$ $-F_{\mathrm{B}}$ and the following expression for $\Delta h / \Delta x$ is obtained:

$$
\begin{aligned}
\frac{\Delta h}{\Delta x}= & \frac{2(h / w) \tau_{\mathrm{S}}+\tau_{0}}{\rho_{\mathrm{I}} g h-(h / w) \tau_{\mathrm{S}}-2 \sigma_{x x}^{\prime}} \\
& +\frac{2 h\left(\sigma_{x x}^{\prime}+\Delta \sigma_{x x}^{\prime}\right)-\frac{1}{2} \rho_{\mathrm{I}} g h^{2}\left(1-\rho_{\mathrm{I}} / \rho_{\mathrm{W}}\right) \phi^{2}}{\left[\rho_{\mathrm{I}} g h-(h / w) \tau_{\mathrm{S}}-2 \sigma_{x x}^{\prime}\right] \Delta x} \\
\approx & \frac{2 \tau_{\mathrm{S}}}{\rho_{\mathrm{I}} g w}+\frac{\tau_{0}}{\rho_{\mathrm{I}} g h}+\frac{2 \Delta \sigma_{x x}^{\prime}}{\rho_{\mathrm{I}} g \Delta x}
\end{aligned}
$$

where $\rho_{\mathrm{I}} g h-(h / w) \tau_{\mathrm{S}}-2 \sigma_{x x}^{\prime} \approx \rho_{\mathrm{I}} g h=\sigma_{0}$ and:

$$
\sigma_{x x}^{\prime}=\frac{1}{4} \rho_{\mathrm{I}} g h\left(1-\rho_{\mathrm{I}} / \rho_{\mathrm{W}}\right) \phi^{2} .
$$

Equations (14) and (15) apply to stream flow, which begins with sheet flow at the head and ends as shelf flow at the foot of a marine ice stream. Stream flow becomes laminar sheet flow when $\tau_{\mathrm{S}}=\sigma_{x x}^{\prime}=\Delta \sigma_{x x}^{\prime} / \Delta x=$ $\phi=0$, in which case Equation (14) can be combined with Equation (6) to produce Equation (7). Stream flow becomes longitudinal shelf flow when $\tau_{\mathrm{S}}=\tau_{0}=$ $\Delta \sigma_{x x}^{\prime} / \Delta x=\Delta h / \Delta x=0$ and $\phi=1$, in which case Equation (14) can be combined with Equation (10) to produce Equation (11).

The unknown variation of $\phi$ along length $L_{\mathrm{S}}$ of stream flow prevents a single simple expression relating $F_{\mathrm{P}}$ to strain rates, such as Equation (7) for sheet flow and Equation (11) for shelf flow. Nevertheless, the pulling power of an ice stream can be appreciated by comparing $\dot{\epsilon}_{x z}$ for sheet flow at the head of an ice stream with $\dot{\epsilon}_{x x}$ for shelf flow at the foot of the ice stream using these equations. In Equation (7), $h=2 \mathrm{~km}$ and $\Delta h / \Delta x=0.005$ are typical at an ice-stream surface inflection line, where the maximum value of $\dot{\epsilon}_{x z}$ at $z=0$ exists for sheet flow. In Equation (11), $h=1 \mathrm{~km}$ is typical at an ice-stream basal grounding line, where the maximum value of $\dot{\epsilon}_{x x}$ exists for unconfined shelf flow. Taking $\rho_{\mathrm{I}}=0.92 \mathrm{Mg} \mathrm{m}^{-3}$, $\rho_{\mathrm{W}}=1.02 \mathrm{Mg} \mathrm{m}^{-3}$, and $n=3$, Equations (7) and (11) then give $\dot{\epsilon}_{x x}=15.6 \dot{\epsilon}_{x z}$ if $\bar{A}$ is the same at both locations. Hence, $\dot{\epsilon}_{x x}$ for maximum shelf flow is an order of magnitude greater than $\dot{\epsilon}_{x z}$ for maximum sheet flow, and the ability of an ice stream to reach far into an ice sheet and pull out ice, its pulling power, is measured by the length $L_{\mathrm{S}}$ of stream flow and how effectively $\dot{\epsilon}_{x x}$ at the grounding line is transmitted along $L_{\mathrm{S}}$.

The one-dimensional force balance considered here as pushing or pulling horizontal gravitational forces, which produce sheet, stream and shelf flow resisted by braking forces, has much in common with the two-dimensional force balance of driving forces and resistive forces analyzed by Whillans (1987) and Van der Veen and Whillans (1989). For example, Whillans (1987) began by stating "Glaciers flow in response to the interaction of gravity, which pulls the glacier forward, and resistive forces, which hold it back." His table I compares the conventional division of stresses into spherical and deviatoric components, on the one hand, with his lithostatic and resistive components, on the other hand, where his lithostatic force is gravitational and gradients in it produce his driving stress for glacial ice. In his figure 2, Whillans (1987) showed a nearly exponential decrease of his driving stress from the ice divide of West Antarctica to the calving front of the Ross Ice Shelf, along a flowline containing Ice Stream B. This same depiction of stream flow as being transitional from sheet flow to shelf flow is shown in Figure 3 as resulting from a general increase in basal buoyancy from the surface-inflection line to the basal grounding line of an ice stream. Specific changes in basal buoyancy, as measured by the change in $d$ along $L_{\mathrm{S}}$ in Figure 3 (bottom), constitute four cases in a spectrum of $\phi$ variations that are possible for ice streams. These four cases will be analyzed in detail.

\section{PULLING POWER AND SURFACE PROFILES}

Pulling force $F_{\mathrm{P}}$ given by Equation (12) applies for stream flow but it does not describe the pulling force adequately because the $\Delta h$ term depends on incremen- 
tal length $\Delta x$ along the ice stream, such that this term vanishes as $\Delta x$ approaches zero, leaving only the $\phi$ term. Hence, the actual pulling force $F_{x}$ is the limit of $F_{\mathrm{P}}$ as $\Delta x \rightarrow 0$ and is:

$$
\begin{aligned}
F_{x} & =\frac{1}{2} \rho_{\mathrm{I}} g w h^{2}\left(1-\rho_{\mathrm{I}} / \rho_{\mathrm{W}}\right) \phi^{2} \\
& =\left(\sigma_{x x}-\sigma_{z z}\right) w h=2 \sigma_{x x}^{\prime} w h
\end{aligned}
$$

where pulling stress $2 \sigma_{x x}^{\prime}$, given by Equation (15), acts on cross-sectional area $w h$. The $G$ term in the vertically integrated force balance (Paterson, 1981, p. 164) is approximately the gradient of $F_{x}$. Hence, the pulling force can be understood in relation to vertically integrated momentum conservation. Mean ice velocity $u$ can be computed to a good approximation by the following expression for conservation of ice flux and steady-state equilibrium:

$$
h u=u_{\mathrm{S}} h_{\mathrm{S}}+(a-b)\left(L_{\mathrm{S}}-x\right)
$$

where $x=0$ at the grounding line of a marine ice stream, $x=L_{\mathrm{S}}$ at the head of the ice stream, where $u_{\mathrm{S}}$ is the mean ice velocity, and rates of accumulation and ablation along $L_{\mathrm{S}}$ are $a$ and $b$, respectively. Entering Equations (16) and (17) into Equation (1) gives the pulling power:

$$
\begin{aligned}
P_{x} & =\frac{1}{2} \rho_{\mathrm{I}} g w h\left(1-\rho_{\mathrm{I}} / \rho_{\mathrm{W}}\right)\left[u_{\mathrm{S}} h_{\mathrm{S}}+(a-b)\left(L_{\mathrm{S}}-x\right)\right] \phi^{2} \\
& =2 \sigma_{x x}^{\prime} w h u .
\end{aligned}
$$

Solutions of Equation (18) require knowing how $h$ varies along $x$ over length $L_{\mathrm{S}}$ of the ice stream. This requires knowing the ice-stream profile.

Surface profiles and the resulting pulling power will be computed for four kinds of marine ice streams:

Case I. Stream flow with minimal basal buoyancy, so that $\phi=0$ along $L_{\mathrm{S}}$.

Case II. Stream flow with decreasing basal buoyancy, such that $\phi=\phi_{\mathrm{G}} \cos ^{2}\left(\pi x / 2 L_{\mathrm{S}}\right)$ along $L_{\mathrm{S}}$.

Case III. Stream flow with equilibrium basal buoyancy, such that $\phi=\left(h_{\mathrm{G}} / h\right) \phi_{\mathrm{G}}$ along $L_{\mathrm{S}}$.

Case IV. Stream flow with maximum basal buoyancy, so that $\phi=\phi_{\mathrm{G}}$ along $L_{\mathrm{S}}$.

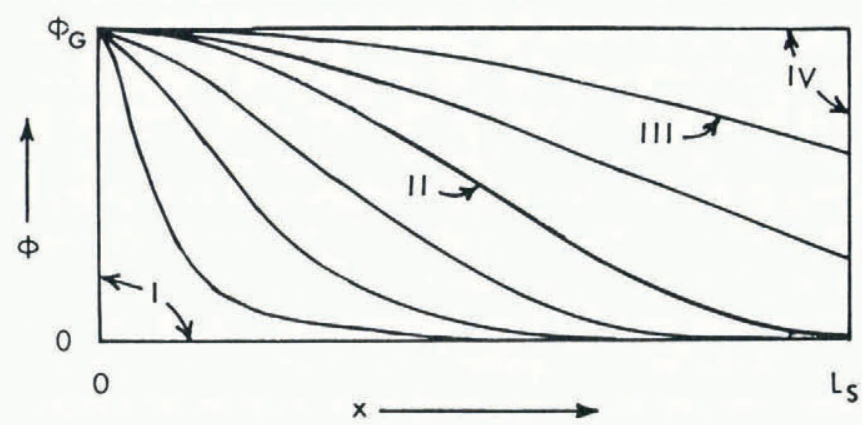

Fig. 5. A possible spectrum of $\phi$ variations along $x$ for ice streams of length $L_{\mathrm{S}}$. The four cases of basal buoyancy shown in Figure 3 (bottom) as average water depths d representative of average basal water pressure are located in this spectrum as shown.

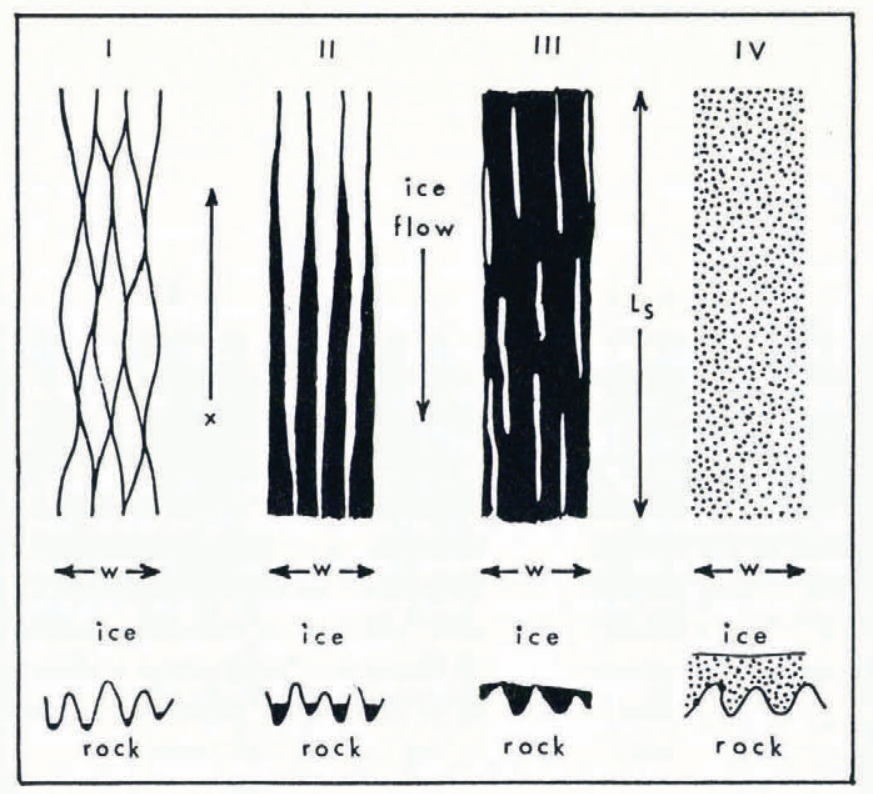

Fig. 6. Four possible cases of basal water configurations shown as average d variations in Figure 3 (bottom) and average $\phi$ variations in Figure 5. Ice-stream beds are shown in plan view (top) and transverse cross-section (bottom), with thin basal water films for which $\phi=0$ shown in white, thick basal water layers for which $\left(h_{\mathrm{G}} / h\right) \phi_{\mathrm{G}}<\phi<\phi_{\mathrm{G}}$ shown in black, and water-saturated till or sediment for which $\phi=\phi_{\mathrm{G}}$ shown as dotted. The vertical is exaggerated.

Subscripts S and G refer to the surface-inflection line and to the basal grounding line, the respective beginning and end of the ice stream.

Cases I through IV belong to a spectrum of $\phi$ variations along length $L_{\mathrm{S}}$ of stream flow, with I and IV being end members of the spectrum, as shown in Figure 5. At this early stage in our understanding of ice streams, it is adventurous to speculate on bed conditions that may produce the $\phi$ spectrum in Figure 5, or other versions of a $\phi$ spectrum, but an attempt to depict possible bed conditions is offered in Figure 6. In all cases, bedrock is depicted as consisting of a series of ridges and troughs elongated along the axis of stream flow, such as mapped seismically beneath Rutford Ice Stream (Doake and others, 1987) and Ice Streams A, B and C (Shabtaie and Bentley, 1988) in West Antarctica (see Fig. 1).

Case I shows the network of narrow water channels along trough bottoms, for which $\phi=\phi_{\mathrm{G}}$ in channels requires a downslope pressure-gradient current, and $\phi \approx 0$ in a water film between water channels, so that $\phi \approx 0$ averaged across width $w$ all along length $L_{\mathrm{S}}$ of the ice stream. This situation exists when decreasing basal water (bottom freezing) and smoother bedrock topography occur in the direction of ice flow.

Case II shows the water channels widening in the direction of ice flow, such that averaged across $w, \phi=0$ where stream flow begins at $x=L_{\mathrm{S}}$ and $\phi=\phi_{\mathrm{G}}$ where stream flow ends at $x=0$. This widening can be caused if increasing basal water (bottom melting) and smoother bedrock topography occur in the direction of ice flow. 
Case III shows wide water channels separated by narrow ridge crests along the entire length $L_{\mathrm{S}}$ of the ice stream, such that $\phi \approx\left(h_{\mathrm{G}} / h\right) \phi_{\mathrm{G}}$ averaged across $w$ along $L_{\mathrm{S}}$. This condition exists when basal water depths nearly match bedrock topographic variations in the direction of ice flow, and no net current exists in the water. It differs from case I only in that more basal water is present all along $L_{\mathrm{S}}$, so that hydrostatic equilibrium is maintained in the water channels (channel water pressure where $h>h_{\mathrm{G}}$ is the same as at $h=h_{\mathrm{G}}$, so there is no pressure-gradient current).

Case IV shows a pad of water-soaked till or sediments between basal ice and bedrock, with deformation and permeability of the pad being such that $\phi=\phi_{\mathrm{G}}$ across $w$ and along $L_{\mathrm{G}}$ (local basal water pressure is that required for the buoyancy of local ice thickness $h$, whereas in case III it is that required for the buoyancy of ice thickness $h_{\mathrm{G}}$ at the grounding line). This situation can exist when permafrost having a high ice fraction becomes thawed, and it requires thawing at $x=L_{\mathrm{S}}$ to produce new meltwater as fast as pad deformation and permeability allow basal water to be discharged at $x=0$. Case IV would then require the surface-inflection line of the ice stream to retreat into the ice sheet, as it is a thermal boundary (the melting isotherm), and this retreat collapses the ice sheet.

The amount of basal water along $L_{\mathrm{S}}$ depends on basal melting and freezing rates in cases I through IV, and in other cases that could be postulated. In cases I, II and III, the basic assumption is that the ice overburden is mostly supported by basal water pressure above water channels and by bedrock between water channels (even though the water film between channels has the overburden ice pressure). These cases require ice-stream applications of subglacial hydrology theories by Weertman (1986), Kamb (1987) and Lliboutry (1987), among others. Case IV can be tested by theories of ice streams on deformable and permeable beds developed by Alley and others (1987), Lingle and Brown (1987), Alley (1989a, b) and MacAyeal (1989), for example.

Figure 7 shows an alternative to Figure 6 for presenting $\phi$ variations in terms of basal water distribution. Bedrock hills and hollows determine the distribution instead of bedrock ridges and troughs aligned in the direction of the ice stream. In case I, lakes exist only in the bottoms of isolated hollows, which act as slippery spots beneath the ice stream and a thin water film exists elsewhere, so that $\phi=0$ along $L_{\mathrm{S}}$. In case II, basal water begins as lakes in isolated hollows and ends surrounding isolated hilltops along $L_{\mathrm{S}}$, with $\phi=\phi_{\mathrm{G}}$ for ice above isolated lakes, $\phi=\left(h_{\mathrm{G}} / h\right) \phi_{\mathrm{G}}$ for ice surrounding isolated hills, and $\phi=0$ for ice in remaining areas where a thin water film allows bedrock to support the ice overburden. In case III, the thin water film exists only on isolated hilltops, which act as sticky spots where $\phi=0$, but for the ice stream in general, $\phi=\left(h_{\mathrm{G}} / h\right) \phi_{\mathrm{G}}$ along $L_{\mathrm{S}}$. In case IV, sediments beneath the ice stream have been eroded away and redeposited as till at the grounding line, leaving basal water in a bedrock trough dammed by a till sill, so $\phi=\phi_{\mathrm{G}}$ along $L_{\mathrm{S}}$ for ice above the trough. Case IV produces fore-deepened troughs in the inter-island channels, straits and fiords of continental shelves that had been glaciated by marine ice sheets. In

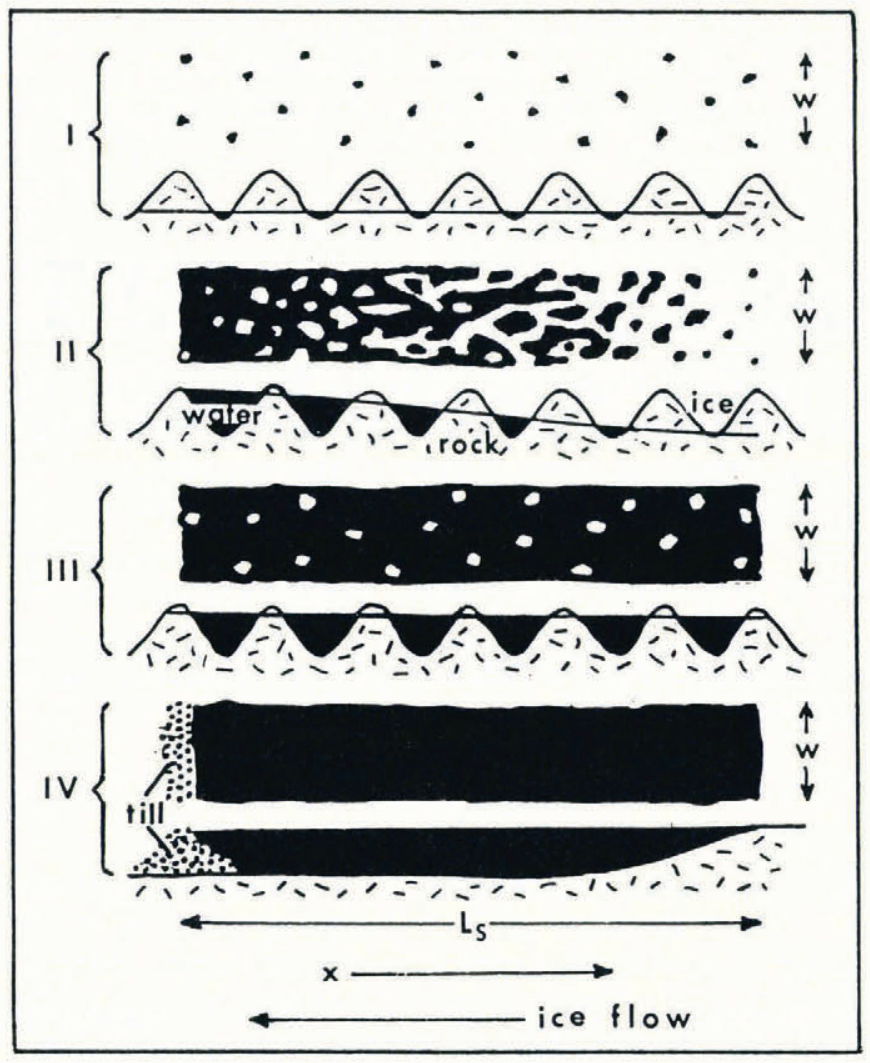

Fig. 7. A basal water configuration in plan view and longitudinal cross-section for the $\phi$ variation of case I through case IV in Figure 5 that is different from the basal water configuration for these cases shown in Figure 6. The bed consists of hills and hollows instead of ridges and valleys, with $\phi=0$ in white areas, $\phi=\left(h_{\mathrm{G}} / h\right) \phi_{\mathrm{G}}$ in connected black areas, and $\phi=\phi_{\mathrm{G}}$ in disconnected black areas, for which $\phi_{\mathrm{G}}=0$. In case IV, basal water is trapped in a glacially eroded trough dammed by glacially deposited sediment till (dotted) at the grounding line, situations found in the inter-island channels and fiords of deglaciated landscapes. The vertical is exaggerated.

these cases, $\phi_{\mathrm{G}}=0$ for ice above isolated bedrock lakes, but $\phi_{\mathrm{G}}>0$ if the till sill is permeable.

A water film over hilltops distributed like islands in a subglacial lake allows the hills to be local "sticky spots" where bedrock bears the ice overburden, and therefore retards ice flow. Applying the Weertman (1986) analysis of basal water pressure to ice streams, the sticky spots in Figure 7 would be the upstream side of bedrock hills, where a thin water film allows bedrock to resist stream flow. Whether this situation exists in ice streams is unknown, but Whillans and Johnsen (1983) observed something like it, possible frozen patches on a thawed bed, in sheet flow near Byrd Station in West Antarctica (see Fig. 1). Vornberger and Whillans (1986) have postulated sticky spots in Ice Stream B (see Fig. 1) as producing bands of surface crevasses.

\section{Case I. Stream flow with minimal basal buoyancy}

Stream flow with $\phi=0$ was used to produce ice-stream 
profiles in the CLIMAP reconstructions of global ice sheets at the last glacial maximum (Hughes, 1981a). Ice streams without basal buoyancy may exist as outlet glaciers through fiords in coastal mountains, where ice is often thick and has a high surface slope for ice streams, implying some traction from a bedrock floor that is rough and may be partly frozen.

Considerable attention has been focused on longitudinal deviator stress $\sigma_{x x}^{\prime}$ and its downslope gradient $\partial \sigma_{x x}^{\prime} / \partial x$ in ice streams, notably by Weertman (1974), Bindschadler and Gore (1982), Alley (1984), Alley and Whillans (1984), McInnes and Budd (1984), Van der Veen (1985, 1987), Muszynski (1987), Muszynski and Birchfield (1987) and Whillans (1987). These studies, notably those of Van der Veen (1987) and Muszynski (1987), show that $\partial\left(h \sigma_{x x}^{\prime}\right) \partial x$ is relatively unimportant in an ice stream. That $\partial\left(h \sigma_{x x}^{\prime}\right) / \partial x$ could be ignored in ice streams fully buttressed by an ice shelf was assumed by Hughes (1981a) in the CLIMAP ice-sheet reconstructions. This assumption was based on the proposition that $\sigma_{x x}^{\prime}$ at the ice-shelf grounding line is the buoyancy pulling stress minus a braking back-stress imposed by the ice shelf:

$$
\left(\sigma_{x x}^{\prime}\right)_{\mathrm{G}}=\frac{1}{4} \rho_{\mathrm{I}} g h_{\mathrm{G}}\left(1-\rho_{\mathrm{I}} / \rho_{\mathrm{W}}\right)-\sigma_{\mathrm{G}}
$$

where $h_{\mathrm{G}}$ and $\sigma_{\mathrm{G}}$ are the ice thickness and the backstress at the grounding line. For full ice-shelf buttressing, Hughes (1981a) assumed that:

$$
\sigma_{\mathrm{G}}=\frac{1}{4} \rho_{\mathrm{I}} g h_{\mathrm{G}}\left(1-\rho_{\mathrm{I}} / \rho_{\mathrm{W}}\right) .
$$

Taking $d=0$ in Equation (3) maximizes ice-bed coupling beneath an ice stream and $\sigma_{\mathrm{G}}$ given by Equation (20) maximizes ice-shelf buttressing beyond an ice stream. Equation (20) holds exactly only when grounding lines completely enclose an ice shelf, making it a "pseudo ice shelf" above a subglacial lake (Robin and others, 1970; Oswald and Robin, 1973). The ice stream has no pulling power in this case.

Equation (19) can be related to the pulling force, given by Equation (16), by requiring that $\phi=\phi_{\mathrm{G}}$ at the grounding line is given by:

$$
\phi_{\mathrm{G}}=\frac{\frac{1}{4} \rho_{\mathrm{I}} g h_{\mathrm{G}}\left(1-\rho_{\mathrm{I}} / \rho_{\mathrm{W}}\right)-\sigma_{\mathrm{G}}}{\frac{1}{4} \rho_{\mathrm{I}} g h_{\mathrm{G}}\left(1-\rho_{\mathrm{I}} / \rho_{\mathrm{W}}\right)} .
$$

A reliable expression for $\sigma_{\mathrm{G}}$ is a major problem in glaciology, because ice shelves have complex shapes and dynamics that impose both form drag and dynamic drag at the grounding line (MacAyeal, 1987). However, in the idealized case of an ice shelf having width $w$ and thickness $h$ identical to $w_{\mathrm{G}}$ and $h_{\mathrm{G}}$ at the grounding line, a balance of forces along floating length $L_{\mathrm{F}}$ from the grounding line to the calving front of the ice shelf gives $\sigma_{\mathrm{G}}=2 \tau_{\mathrm{S}}\left(L_{\mathrm{F}} / w_{\mathrm{G}}\right)$, where side shear stress $\tau_{\mathrm{S}}$ is assumed to be constant along $L_{\mathrm{F}}$ (Thomas, 1977). Values of $\sigma_{\mathrm{G}}$ for the Ross Ice Shelf in Antarctica have been computed from field data by Thomas and MacAyeal (1982) and by Jezek (1984).

The concave surface profile that is characteristic of stream flow can be produced even if $\phi=\phi_{\mathrm{G}}=0$. As seen in Equation (3), $\phi \rightarrow 0$ exists when $d \rightarrow 0$, a physical condition in which the basal water is thick enough to drown bedrock projections that control the basal sliding velocity, but not the large projections, which therefore continue to support nearly all of the ice overburden. For smaller projections, the ice overburden is supported by the water layer. Hence, the fast sliding velocity of an ice stream can be attained without ubiquitous basal buoyancy, provided there is no ice-shelf buttressing $\left(\phi_{\mathrm{G}}=1\right)$ and the basal water film drowns rate-controling bedrock projections (Weertman, 1986).

In ice streams reconstructed for CLIMAP, the bed was assumed to be rigid, impermeable and rough in the manner specified in the basal sliding theory for sheet flow proposed by Weertman (1957b). Basal sliding for stream flow was attained by having the bedrock projections of height $\Lambda$, that control the sliding velocity for sheet flow, be progressively drowned in the downslope direction by a basal water layer of thickness $\lambda$ that increased from $\lambda \approx 0$ at $x=L_{\mathrm{S}}$ to $\lambda=\Lambda$ at $x=0$ along the ice stream. The variation of $\lambda$ with $x$ over length $L_{\mathrm{S}}$ was unknown, but on the assumption that $\partial \lambda / \partial x=0$ at both $x=L_{\mathrm{S}}$ and $x=0$, where $x=0$ was the grounding line, the following cosine variation was employed:

$$
\lambda=\frac{1}{2} \Lambda\left[1+\cos \left(\pi x / L_{\mathrm{S}}\right)\right]=\Lambda \cos ^{2}\left(\pi x / 2 L_{\mathrm{S}}\right) .
$$

The undrowned height of these projections was $\Lambda-\lambda$, and the bed-roughness factor for stream flow would then be:

$$
\begin{aligned}
\frac{\Lambda-\lambda}{\Lambda^{\prime}} & =\frac{\Lambda}{\Lambda^{\prime}}\left[1-\cos ^{2}\left(\frac{\pi x}{2 L_{\mathrm{S}}}\right)\right] \\
& =\frac{\Lambda}{\Lambda^{\prime}} \sin ^{2}\left(\frac{\pi x}{2 L_{\mathrm{S}}}\right)
\end{aligned}
$$

where $\Lambda^{\prime}$ was the distance between projections of height $\Lambda$ and $\Lambda / \Lambda^{\prime}$ was a constant bed-roughness factor for sheet flow in the Weertman (1957b) theory.

Basal sliding velocity $u_{0}$ for sheet flow in the Weertman (1957b) theory was:

$$
u_{0}=\left(\frac{\tau_{0}}{B}\right)^{m}=\left[\left(\frac{\Lambda^{\prime}}{\Lambda}\right)^{2} \frac{\tau_{0}}{B_{0}}\right]^{m}
$$

where $m=\frac{1}{2}(n+1), B=B_{0}\left(\Lambda / \Lambda^{\prime}\right)^{2}$ and $B_{0}$ was a constant that probably depended on basal water pressure (Budd and others, 1979). In CLIMAP ice-sheet reconstructions, Equations (6) and (24) were used to compute convex surface flowline profiles characteristic of sheet flow from a formula proposed by Nye (1952). For a horizontal bed, the case considered here, his formula was:

$$
\frac{\Delta h}{\Delta x}=\frac{\tau_{0}}{\rho_{1} g h} .
$$

The CLIMAP reconstructions assumed that basal shear stress $\tau_{0}$ had two characteristic variations for sheet flow from the ice divide at $x=L$ to the ice margin at $x=0$, one being $\tau_{\mathrm{F}}$ for a frozen bed computed from Equation (6) and the other being $\tau_{\mathrm{M}}$ for a melted bed computed from Equation (24). If the bed consisted of mixed frozen and thawed patches, as may exist in transition zones bet- 
ween zones where the bed is either completely frozen or completely thawed, then:

$$
\tau_{0}=f \tau_{\mathrm{M}}+(1-f) \tau_{\mathrm{F}}
$$

where $f$ was the thawed fraction in a given $\Delta x$ step of Equation (25).

Ablation in the CLIMAP ice sheets was confined to the first step in from the ice-sheet margin, with accumulation being constant over all subsequent steps to the ice divide. This constraint was replaced by Hughes (1981b), and Table 1 lists the $\tau_{\mathrm{M}}$ and $\tau_{\mathrm{F}}$ expression for the massbalance expression:

$$
a(L-E)+b E=N
$$

where the equilibrium line is at $x=E$, accumulation rate $a$ is constant over flow-band length $L-E$, ablation rate $b$ is constant over flow-band length $E$ and net mass balance $N$ is zero for a steady-state ice sheet, positive for an advancing ice sheet and negative for a retreating ice sheet.

Stream flow develops from sheet flow over a thawed bed, and $E=h_{\mathrm{E}}=b=0$ in ice streams buttressed by ice shelves, which was the case for CLIMAP ice sheets. Applying these limitations to $\tau_{\mathrm{M}}$ in Table 1 gives:

$$
\begin{aligned}
& \tau_{\mathrm{M}}= \\
& \quad\left[\frac{(m+1) \rho_{\mathrm{I}} g a^{2} B_{0}^{2 m}\left(\Lambda / \Lambda^{\prime}\right)^{4 m}(L-x)^{(2 m+1) / m}}{(2 m+1)\left[L^{(m+1) / m}-(L-x)^{(m+1) / m}\right]}\right]^{1 /(2 m+1)} .
\end{aligned}
$$

Since $\Lambda / \Lambda^{\prime}$ is raised to the $4 m /(2 m+1)$ power in Equation (28) for sheet flow in which bedrock projections $\Lambda$ are not drowned, progressive drowning for stream flow according to Equation (22) requires that $\Lambda-\lambda$ replaces $\Lambda$ as the undrowned height. Then, from Equations (23) and (28):

$$
\tau_{0}=\tau_{\mathrm{M}}\left[\sin ^{2}\left(\frac{\pi x}{2 L_{\mathrm{S}}}\right)\right]^{4 m /(2 m+1)} .
$$

Substituting this expression for $\tau_{0}$ into Equation (25) gives:

$$
\frac{\Delta h}{\Delta x}=\frac{\tau_{\mathrm{M}}}{\rho_{\mathrm{I}} g h}\left[\sin ^{2}\left(\frac{\pi x}{2 L_{\mathrm{S}}}\right)\right]^{4 m /(2 m+1)}
$$

Equation (30) converts the convex sheet-flow profile over length $L$ given by $\tau_{\mathrm{M}}$ in Equation (28) into a concave stream-flow profile over length $L_{\mathrm{S}}$. This is the concave profile for $\phi=0$, so that $P_{x}=0$ in Equation (18).

\section{Case II. Stream flow with decreasing basal buoyancy}

An expression for $\Delta h / \Delta x$ can be derived by using the continuity condition to specify $\sigma_{x x}^{\prime}$ in Equation (15). For constant $w$, the continuity equation is:

$$
\partial(h u) / \partial x-a=0
$$

where $u$ is the average velocity of the ice column for mass-balance equilibrium. Integrating Equation (31) for

Table 1. Variations of basal shear stress $\tau_{0}$ with distance $x$ along flow bands of length $L$ and constant width for sheet flow over frozen $\left(\tau_{0}=\tau_{\mathrm{F}}\right)$ and thawed $\left(\tau_{0}=\tau_{\mathrm{M}}\right)$ beds for constant surface accumulation and ablation rates $a$ and $b$ separated by an equilibrium line at distance $x=E$ from the margin of the ice sheet (Hughes, 1981b)*

For the ablation zone $(0 \leq x \leq E)$ :

$$
\begin{aligned}
\tau_{\mathrm{F}} & =\frac{A[(1+n / 2)(N-b x)]^{1 / n}}{\left\{h_{\mathrm{E}}^{(2 n+2) / n}+\left(2 A / \rho_{\mathrm{I}} g b\right)(1+n / 2)^{1 / n}\left[(N-b x)^{(n+1) / n}-(N-b E)^{(n+1) / n}\right]\right\}^{1 /(n+1)}} \\
\tau_{\mathrm{M}} & =\frac{B(N-b x)^{1 / m}}{\left\{h_{\mathrm{E}}^{(2 m+1) / m}+\left[(2 m+1) B /(m+1) \rho_{\mathrm{I}} g b\right]\left[(N-b x)^{(m+1) / m}-(N-b E)^{(m+1) / m}\right]\right\}^{1 /(2 m+1)}}
\end{aligned}
$$

For the accumulation zone $(E \leq x \leq L)$ :

$$
\begin{aligned}
\tau_{\mathrm{F}} & =\frac{A[(1+n / 2)(L-x)]^{1 / n}}{\left\{h_{\mathrm{E}}^{(2 n+2) / n}+\left(2 A / \rho_{\mathrm{I}} g\right)(a+a n / 2)^{1 / n}\left[(L-E)^{(n+1) / n}-(L-x)^{(n+1) / n}\right]\right\}^{1 /(n+1)}} \\
\tau_{\mathrm{M}} & =\frac{B[a(L-x)]^{1 / m}}{\left\{h_{\mathrm{E}}^{(2 m+1) / m}+\left[(2 m+1) B a^{1 / m} /(m+1) \rho_{\mathrm{I}} g\right]\left[(L-E)^{(m+1) / m}-(L-x)^{(m+1) / m}\right]\right\}^{1 /(2 m+1)}}
\end{aligned}
$$

* The sign after the $h_{\mathrm{E}}$ term was incorrectly a minus in Hughes (1981b). 
constant $a$ over length $L_{\mathrm{S}}$ and noting that $u$ is negative:

$$
\int_{0}^{x} a \mathrm{~d} x=a x=\int_{h_{\mathrm{G}} u_{\mathrm{G}}}^{h u} \mathrm{~d}(h u)=h u-h_{\mathrm{G}} u_{\mathrm{G}}
$$

where $h_{\mathrm{G}}$ and $u_{\mathrm{G}}$ are values of $h$ and $u$ at the grounding line. Equation (31) also yields:

$$
a=h \partial u / \partial x+u \partial h / \partial x=h \dot{\epsilon}_{x x}+u \Delta h / \Delta x
$$

where $\dot{\epsilon}_{x x}=\partial u / \partial x$ is the longitudinal strain-rate and is given by Equation (10), in which $\tau$ is the effective shear stress and $\sigma_{x x}^{\prime}$ is the longitudinal deviator stress. For constant width, the transverse deviator stress $\sigma_{y y}^{\prime}$ is zero:

$$
\sigma_{y y}^{\prime}=\sigma_{y y}-\bar{\sigma}=\sigma_{y y}-\frac{1}{3}\left(\sigma_{x x}+\sigma_{y y}+\sigma_{z z}\right)=0
$$

where $\bar{\sigma}=\frac{1}{3}\left(\sigma_{x x}+\sigma_{y y}+\sigma_{z z}\right)$ is the depth-averaged hydrostatic pressure. Solving Equation (34) for $\sigma_{y y}$ yields:

$$
\sigma_{y y}=\frac{1}{2}\left(\sigma_{x x}+\sigma_{z z}\right)
$$

Important stress components in $\tau$ are $\sigma_{x y}, \sigma_{x z}, \sigma_{x x}, \sigma_{y y}$ and $\sigma_{z z}$. Using Equation (35):

$$
\begin{aligned}
\tau^{2}= & \sigma_{x y}^{2}+\sigma_{y z}^{2}+\sigma_{z x}^{2} \\
& \quad+\frac{1}{6}\left[\left(\sigma_{x x}-\sigma_{y y}\right)^{2}+\left(\sigma_{y y}-\sigma_{z z}\right)^{2}+\left(\sigma_{z z}-\sigma_{x x}\right)^{2}\right] \\
= & \sigma_{x y}^{2}+\sigma_{x z}^{2}+\frac{1}{4}\left(\sigma_{x x}-\sigma_{z z}\right)^{2} .
\end{aligned}
$$

Using Equation (35) to express $\sigma_{x x}^{\prime}$ in terms of $\sigma_{x x}$ and $\sigma_{z z}$ :

$$
\begin{aligned}
\sigma_{x x}^{\prime}=\sigma_{x x}-\bar{\sigma} & =\sigma_{x x}-\frac{1}{3}\left(\sigma_{x x}+\sigma_{y y}+\sigma_{z z}\right) \\
& =\frac{1}{2}\left(\sigma_{x x}-\sigma_{z z}\right) .
\end{aligned}
$$

Equation (10) now becomes:

$$
\begin{aligned}
\dot{\epsilon}_{x x}=[ & \left.\left(\sigma_{x x}-\sigma_{z z}\right) / 2 A^{n}\right] \\
& \cdot\left[\sigma_{x y}^{2}+\sigma_{x z}^{2}+\frac{1}{4}\left(\sigma_{x x}-\sigma_{z z}\right)^{2}\right]^{(n-1) / 2} .
\end{aligned}
$$

Equations (32) and (33) can be solved for $\Delta h / \Delta x$, and Equation (38) can be substituted for $\dot{\epsilon}_{x x}$ in the resulting expression to give:

$$
\begin{aligned}
\frac{\Delta h}{\Delta x}= & \frac{a-h \dot{\epsilon}_{x x}}{u}=\frac{h\left(a-h \dot{\epsilon}_{x x}\right)}{h_{\mathrm{G}} u_{\mathrm{G}}+a x} \\
= & \frac{h a-h^{2}\left[\left(\sigma_{x x}-\sigma_{z z}\right) / 2 A^{n}\right]}{h_{\mathrm{G}} u_{\mathrm{G}}+a x} \\
& \cdot \frac{\left[\sigma_{x y}^{2}+\sigma_{x z}^{2}+\frac{1}{4}\left(\sigma_{x x}-\sigma_{z z}\right)^{2}\right]^{(n-1) / 2}}{h_{\mathrm{G}} u_{\mathrm{G}}+a x} .
\end{aligned}
$$

Equation (39) is difficult to evaluate further.

A major simplification of Equation (39) is possible if the braking effect of shear stresses $\sigma_{x y}$ and $\sigma_{x z}$ can be represented by a longitudinal braking stress $\sigma_{\mathrm{B}}$ that reduces pulling by the gravity-driven longitudinal deviator stress $\sigma_{x x}^{\prime}=\frac{1}{2}\left(\sigma_{x x}-\sigma_{z z}\right)$ given by Equation (15). This implies a longitudinal braking force $F_{\mathrm{B}}$ that arises from side and basal traction and increases with distance $x$ up- stream from the grounding line as follows:

$$
F_{\mathrm{B}}=\sigma_{\mathrm{B}} w h=2 \bar{\tau}_{\mathrm{S}} \bar{h} x+\bar{\tau}_{0} w x
$$

where $\bar{\tau}_{\mathrm{S}}, \bar{h}$ and $\bar{\tau}_{0}$ are the average values of $\tau_{\mathrm{S}}, h$ and $\tau_{0}$ over distance $x$. Equation (39) can then be replaced by:

$$
\begin{aligned}
\frac{\Delta h}{\Delta x} & =\frac{h a-h^{2}\left[\left(\sigma_{x x}^{\prime}-\sigma_{\mathrm{B}}\right) / A\right]^{n}}{h_{\mathrm{G}} u_{\mathrm{G}}+a x} \\
& =\frac{h a-h^{2}\left[\sigma_{x x}^{\prime}-2 \bar{\tau}_{\mathrm{S}}(\bar{h} x / h w)-\bar{\tau}_{0}(x / h)\right]^{n} / A^{n}}{h_{\mathrm{G}} u_{\mathrm{G}}+a x} .
\end{aligned}
$$

There is no mathematical way to derive Equation (41) from Equation (39), but physically it means that the braking effect of shear stresses $\sigma_{x y}$ and $\sigma_{x z}$ in restraining stream flow is mimicked if $\sigma_{x x}^{\prime}$ is reduced by $\sigma_{\mathrm{B}}$.

Since $\tau_{0}$ results from basal traction caused by icebed coupling due to the weight of ice above buoyancy height being supported by the bed, the effect of $\bar{\tau}_{0}$ in Equation (41) is included if $\sigma_{x x}^{\prime}$ is given by Equation (15). Equation (41) then becomes:

$$
\begin{aligned}
& \frac{\Delta h}{\Delta x}= \\
& \frac{h a-h^{2}\left[\frac{1}{4} \rho_{\mathrm{I}} g h\left(1-\rho_{\mathrm{I}} / \rho_{\mathrm{W}}\right) \phi^{2}-2 \bar{\tau}_{\mathrm{S}}(\bar{h} x / h w) \phi^{2}\right]^{n} / A^{n}}{h_{\mathrm{G}} u_{\mathrm{G}}+a x}
\end{aligned}
$$

where $\phi$ expresses the degree of ice-bed coupling and iceshelf buttressing, and is included in the $\bar{\tau}_{\mathrm{S}}$ term because the braking force cannot exceed the pulling force.

The variation of $\tau_{\mathrm{S}}$ along $x$ can be represented as a smooth decrease from a maximum at the head of the ice stream, where converging flow has produced strainhardened ice having an upper viscoplastic yield stress $\left(\tau_{\mathrm{v}}\right)_{\mathrm{S}}$ at $x=L_{\mathrm{S}}$, to a minimum at the foot of the ice stream, where laminar flow has produced strain-softened ice having a lower viscoplastic yield stress $\left(\tau_{\mathrm{v}}\right)_{\mathrm{G}}$ at $x=0$. An empirical expression that represents this transition is:

$$
\tau_{\mathrm{S}}=\left(\tau_{\mathrm{v}}\right)_{\mathrm{G}}+\left[\left(\tau_{\mathrm{v}}\right)_{\mathrm{S}}-\left(\tau_{\mathrm{v}}\right)_{\mathrm{G}}\right] \sin ^{2}\left(\pi x / 2 L_{\mathrm{S}}\right) .
$$

If strain hardening remains all along $L_{\mathrm{S}}$, then $\left(\tau_{\mathrm{v}}\right)_{\mathrm{S}}=$ $\left(\tau_{\mathrm{v}}\right)_{\mathrm{G}}=\tau_{\mathrm{v}}$ and $\tau_{\mathrm{S}}=\tau_{\mathrm{v}}$. If strain softening ends as shear rupture at the grounding line, $\left(\tau_{\mathrm{v}}\right)_{\mathrm{G}}=0$ and $\tau_{\mathrm{S}}=\tau_{\mathrm{v}} \sin ^{2}\left(\pi x / 2 L_{\mathrm{S}}\right)$. If shear rupture occurs all along $L_{\mathrm{S}}$, then $\left(\tau_{\mathrm{v}}\right)_{\mathrm{S}}=\left(\tau_{\mathrm{v}}\right)_{\mathrm{G}}=0$ and $\tau_{\mathrm{S}}=0$. This spectrum of $\tau_{S}$ behavior obtained from Equation (43) is illustrated by the flow curves in Figure 8, in which increasing strain softening allows a given side shear strain $\epsilon_{x y}$ to be produced by decreasing side shear stresses $\tau_{\mathrm{S}}$.

The average value of $\tau_{\mathrm{S}}$ is provided by the relationship:

$$
\bar{\tau}_{\mathrm{S}} x=\int_{0}^{x} \tau_{\mathrm{S}} \mathrm{d} x .
$$

Substituting $\tau_{\mathrm{S}}$ from Equation (43) for $\tau_{\mathrm{S}}$ in Equation (44) gives:

$$
\left.\bar{\tau}_{\mathrm{S}}=\left(\tau_{\mathrm{v}}\right)_{\mathrm{G}}+\left[\left(\tau_{\mathrm{v}}\right)_{\mathrm{S}}-\tau_{\mathrm{v}}\right)_{\mathrm{G}}\right]\left[\frac{1}{2}-\frac{1}{2}\left(L_{\mathrm{S}} / \pi x\right)\right] \sin \left(\pi x / 2 L_{\mathrm{S}}\right)
$$

for which $\bar{\tau}_{\mathrm{S}}=0$ at $x=0$ and $\bar{\tau}_{\mathrm{S}}=\frac{1}{2}\left(\tau_{\mathrm{v}}\right)_{\mathrm{S}}$ at $x=S$. 


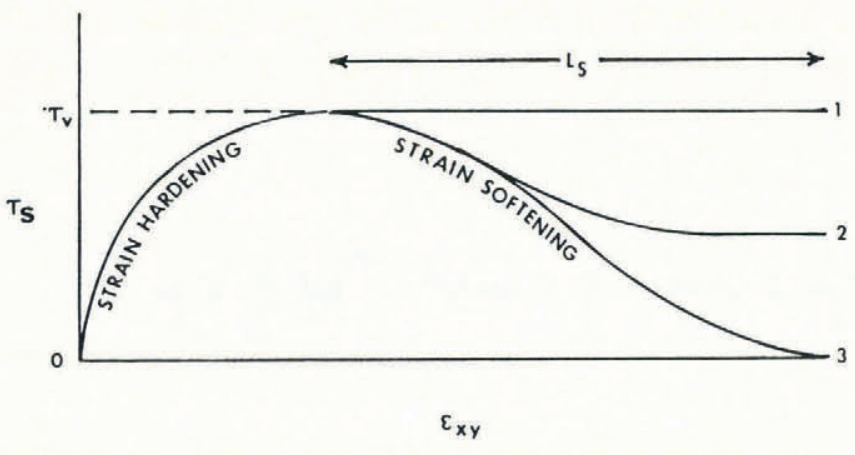

Fig. 8. Possible flow curves for lateral shear in an ice stream. Strain hardening in the zone of converging flow at the head of an ice stream causes an increase in side-shear stress $\tau_{\mathrm{S}}$ and transverse shear strain $\epsilon_{x y}$ until viscoplastic yield stress $\tau_{\mathrm{v}}$ is reached. Over length $L_{\mathrm{S}}$ of stream flow, $\tau_{\mathrm{S}}$ is constant if strain hardening and softening rates are in balance (curve 1), $\tau_{\mathrm{S}}$ decreases if strain softening dominates (curves 2 and 3 ) and $\tau_{\mathrm{S}}$ drops to zero if strain softening leads to shear rupture (curve 3 ).

Strain softening along $x$ is not necessarily described by Equation (45). It can be related to the minimum value of $\tau_{\mathrm{S}}$ if $\bar{h}$ is replaced by mean height $\frac{1}{2}\left(h+h_{\mathrm{G}}\right)$ and side-strain softening controls the side-shear force such that:

$$
2 \bar{\tau}_{\mathrm{S}} \bar{h} x=\left(\tau_{\mathrm{v}}\right)_{\mathrm{G}}\left(h+h_{\mathrm{G}}\right) x .
$$

Figure 9 shows the effect of Equation (46) as $x$ increases in successive $\Delta x$ steps. The mean side area is $\left(h_{1}+h_{\mathrm{G}}\right) \Delta x$ for the first step and $\left(h_{\mathrm{S}}+h_{\mathrm{G}}\right) L_{\mathrm{S}}$ for the last step. The side area along $x$ is overestimated more with each step if the ice-stream surface is highly concave. Progressive overestimation of side area offsets keeping $\tau_{\mathrm{S}}$ at its minimum in a way that links strain softening to the concavity of the ice stream. The sooner strain softening develops in its side-shear zones, the more concave the ice stream becomes. This is reasonable, because the ultimate strain softening is shear rupture, for which $\tau_{\mathrm{S}}=0$ and Equation (42) has the most concave profile.

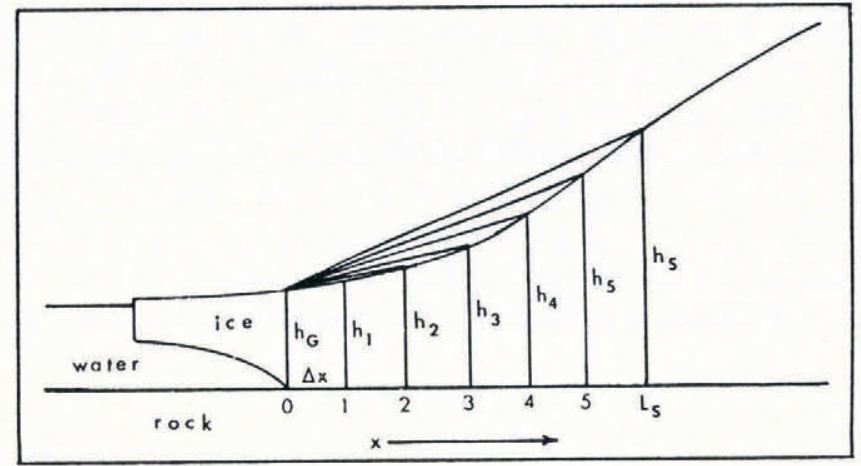

Fig. 9. A method for approximating the side area of an ice stream that uses successive straight lines to represent the concave top surface, with one line for each additional $\Delta x$ increment added to $x$. The less concave the surface, the better the approximation.
Case II is a situation in which basal permafrost thaws to produce a layer of water-soaked sediments through which bedrock crops out. An ice stream develops, with some of the ice overburden supported by these bedrock "sticky spots" and the remainder supported by basal pore-water pressure. Hence, $\tau_{0}$ exists and its variation along $x$ can be represented by modifying Equation (28), in which $\tau_{0}=\tau_{\mathrm{M}}$ for a thawed bed, to include the effect of basal buoyancy that arises when basal permafrost thaws. Since the basal permafrost consists of unconsolidated sediments with a high ice fraction, thawing allows the basal water pressure to support the entire ice overburden except at those sticky spots where bedrock projects through the sediments and penetrates the overlying ice. If $\Lambda$ is the height of these bedrock projections and $\Lambda^{\prime}$ is their average separation, and if $\lambda$ is the thickness of thawed water-soaked sediments between these projections, they can be related to basal buoyancy factor $\phi$ as follows:

$$
\frac{\Lambda-\lambda}{\Lambda^{\prime}}=\frac{\Lambda}{\Lambda^{\prime}}\left(1-\frac{\phi}{\phi_{\mathrm{G}}}\right) .
$$

Equation (47) requires that $\lambda=0$ when $\phi=0$ for no buoyancy and $\lambda=\Lambda$ when $\phi=\phi_{\mathrm{G}}$ for full buoyancy, with a linear variation in between. Equation (28) can be modified to include this situation so that the following expression for $\tau_{0}$ results:

$$
\begin{aligned}
\tau_{0}= & {\left[( m + 1 ) \rho _ { \mathrm { I } } g a ^ { 2 } B _ { 0 } ^ { 2 m } \left[\left(\Lambda / \Lambda^{\prime}\right)\right.\right.} \\
& \left.\left.\cdot\left(1-\phi / \phi_{\mathrm{G}}\right)\right]^{4 m}(L-x)^{(2 m+1) / m}\right]^{1 /(2 m+1)} \\
& /\left[(2 m+1)\left[L^{(m+1) / m}-(L-x)^{(m+1) / m}\right]\right]^{1 /(2 m+1)} \\
= & {\left[\frac{(m+1) \rho_{\mathrm{I}} g a^{2} B^{2 m}(L-x)^{(2 m+1) / m}}{(2 m+1)\left[L^{(m+1) / m}-(L-x)^{(m+1) / m}\right]}\right]^{1 /(2 m+1)} } \\
& \cdot\left[1-\frac{\phi}{\phi_{\mathrm{G}}}\right]^{4 m /(2 m+1)} \\
= & \tau_{\mathrm{M}}\left(1-\phi / \phi_{\mathrm{G}}\right)^{4 m /(2 m+1)}
\end{aligned}
$$

where $B=B_{0}\left(\Lambda / \Lambda^{\prime}\right)^{2}$ in the Weertman (1957b) theory of basal sliding. This assumes the large "sticky-spot" bedrock projections that control stream flow have a height $\Lambda-\lambda$ penetrating ice above thawed permafrost that is comparable to the "controling obstacle height" for sheet flow that Weertman (1957b) proposed.

An expression for $\Delta h / \Delta x$ in which stream flow begins as sheet flow and ends as shelf flow is the following:

$$
\begin{aligned}
& \frac{\Delta h}{\Delta x}= \\
& \frac{h a-h^{2}\left[\frac{1}{4} \rho_{\mathrm{I}} g h\left(1-\rho_{\mathrm{I}} / \rho_{\mathrm{W}}\right)-\left(\tau_{\mathrm{v}}\right)_{\mathrm{G}}\left(1+h_{\mathrm{G}} / h\right) x / w\right]^{n} \phi^{2 n} / A^{n}}{h_{\mathrm{G}} u_{\mathrm{G}}+a x} \\
& \quad+\frac{\tau_{\mathrm{M}}\left(1-\phi / \phi_{\mathrm{G}}\right)^{4 m /(2 m+1)}}{\rho_{\mathrm{I}} g h}
\end{aligned}
$$

where Equation (46) is substituted into Equation (42), Equation (48) is substituted into Equation (25) and the two are added. Since braking vanishes when pulling vanishes, $\left(\tau_{\mathrm{v}}\right)_{\mathrm{G}}=0$ when $\phi=0$. In Equation (49), sheet 
flow exists when $\phi=0$ and the second righthand term dominates, whereas shelf flow exists when $\phi=\phi_{\mathrm{G}}$ and that term vanishes. Since braking stops when pulling stops, the limiting ice-stream length is:

$$
L_{\mathrm{S}}=x=\frac{\rho_{\mathrm{I}} g h w\left(1-\rho_{\mathrm{I}} / \rho_{\mathrm{W}}\right)}{4\left(\tau_{\mathrm{v}}\right)_{\mathrm{G}}\left(1+h_{\mathrm{G}} / h\right)} .
$$

If $\left(\tau_{\mathrm{v}}\right)_{\mathrm{G}}=100 \mathrm{kPa}, h_{\mathrm{G}}=1000 \mathrm{~m}, h=2000 \mathrm{~m}$ and $w=$ $30 \mathrm{~km}, L_{\mathrm{S}}=100 \mathrm{~km}$.

Many ways to decrease $\phi$ as $x$ increases along length $L_{\mathrm{S}}$ of stream flow are possible, but one for which $d=$ $\left(\rho_{\mathrm{I}} / \rho_{\mathrm{W}}\right) h_{\mathrm{G}} \cos ^{2}\left(\pi x / 2 L_{\mathrm{S}}\right)$ so that in Equation (3) both $\phi$ and $\mathrm{d} \phi / \mathrm{d} x$ are smooth functions is:

$$
\phi=\phi_{\mathrm{G}} \cos ^{2}\left(\pi x / 2 L_{\mathrm{S}}\right) .
$$

Basal water pressure decreases gradually from $\sigma_{0}=$ $\rho_{\mathrm{I}} g h_{\mathrm{G}}$ at $x=0$ to $\sigma_{0}=0$ at $x=L_{\mathrm{S}}$. Equation (49) becomes:

$$
\begin{aligned}
\frac{\Delta h}{\Delta x}=\{ & h a-h^{2}\left[\frac{1}{4} \rho_{\mathrm{I}} g h\left(1-\rho_{\mathrm{I}} / \rho_{\mathrm{W}}\right)-\left(\tau_{\mathrm{v}}\right)_{\mathrm{G}}\left(1+h_{\mathrm{G}} / h\right) x / w\right]^{n} \\
& \left.\cdot\left[\phi_{\mathrm{G}}^{2} \cos ^{4}\left(\pi x / 2 L_{\mathrm{S}}\right)\right]^{n} / A^{n}\right\} /\left\{h_{\mathrm{G}} u_{\mathrm{g}}+a x\right\} \\
+ & \frac{\tau_{\mathrm{M}}}{\rho_{\mathrm{I}} g h}\left[\sin ^{2}\left(\frac{\pi x}{2 L_{\mathrm{S}}}\right)\right]^{4 m /(2 m+1)}
\end{aligned}
$$

\section{Case III. Stream flow with equilibrium basal buoyancy}

If bedrock "sticky spots" cropping out in the watersoaked sediments beneath an ice stream are small and widely separated, or are not even present, and if the permeability of the sediments allows the pore-water pressure to be in hydrostatic equilibrium with basal water pressure at the grounding line, then $d=\left(\rho_{\mathrm{I}} / \rho_{\mathrm{W}}\right) h_{\mathrm{G}}$ all along $L_{\mathrm{S}}$ and Equation (3) becomes:

$$
\phi=\phi_{\mathrm{G}}\left(h_{\mathrm{G}} / h\right)
$$

This is the case of constant basal water pressure, for which Equation (49) becomes:

$$
\begin{aligned}
& \frac{\Delta h}{\Delta x}= \\
& \qquad h a-h^{2}\left[\frac{1}{4} \rho_{\mathrm{I}} g h\left(1-\rho_{\mathrm{I}} / \rho_{\mathrm{W}}\right)-\left(\tau_{\mathrm{v}}\right)_{\mathrm{G}}\left(1+h_{\mathrm{G}} / h\right) x / w\right]^{n} \\
& \left.\quad \cdot\left[\phi_{\mathrm{G}}\left(h_{\mathrm{G}} / h\right)\right]^{n} / A^{n}\right\} /\left\{h_{\mathrm{G}} u_{\mathrm{G}}+a x\right\} \\
& \quad+\frac{\tau_{\mathrm{M}}\left(1-h_{\mathrm{G}} / h\right)^{4 m /(2 m+1)}}{\rho_{\mathrm{I}} g h} .
\end{aligned}
$$

\section{Case IV. Stream flow with maximum basal buoyancy}

If bedrock does not crop out in the water-soaked sediments beneath an ice stream, and a till or bedrock sill at its grounding line is too impermeable to pore water in the sediments to establish hydrostatic equilibrium under the ice stream, then pore-water pressure supports all of the ice overburden. In this case, $d=\left(\rho_{\mathrm{I}} / \rho_{\mathrm{W}}\right) h$ all along $L_{\mathrm{S}}$, so no ice-bed coupling exists and $\phi$ in Equation (3) reduces to its value for ice-shelf buttressing:

$$
\phi=\phi_{\mathrm{G}}
$$

This is the case of maximum basal water pressure, for which Equation (49) reduces to:

$$
\begin{aligned}
& \frac{\Delta h}{\Delta x}= \\
& \qquad h a-h^{2}\left[\frac{1}{4} \rho_{\mathrm{I}} g h\left(1-\rho_{\mathrm{I}} / \rho_{\mathrm{W}}\right)-\left(\tau_{\mathrm{v}}\right)_{\mathrm{G}}\left(1+h_{\mathrm{G}} / h\right) x / w\right]^{n} \\
& \left.\quad \cdot \phi_{\mathrm{G}}^{2 n} / A^{n}\right\} /\left\{h_{\mathrm{G}} u_{\mathrm{G}}+a x\right\} .
\end{aligned}
$$

\section{PULLING POWER AND A LIFE-CYCLE CLASSIFICATION FOR ICE STREAMS}

Pulling power provides an analytical foundation for classifying marine ice streams in a hierarchy in which loss of gravitational potential energy over time produces an icestream history characterized by inception, growth, mature, declining and terminal stages of a life cycle, but allowing for rejuvenation as well. Pulling power decreases as an ice stream ages, and quantifies the vitality of the ice stream at a given stage in its life cycle. The life cycle of an ice stream must be inferred from present-day ice streams and from the glacial geological record of former ice streams. These observations support an hypothesis in which the pulling power of an ice stream is closely related to the degree of ice-bed coupling beneath the ice stream and the degree of ice-shelf buttressing beyond the ice stream. Letting numbers 1, 2, 3, 4 and 5 denote no, weak, moderate, strong and full ice-bed coupling, and letters $\mathrm{A}, \mathrm{B}, \mathrm{C}, \mathrm{D}$ and $\mathrm{E}$ denote no, weak, moderate, strong and full ice-shelf buttressing. Table 2 presents a life-cycle classification of ice streams in which various combinations of ice-bed coupling and ice-shelf buttressing are quantified as values of $\phi$. In this classification of an ice-stream life cycle, $\phi=1$ for the inception stage, $\phi=3 / 4$ for growth stages, $\phi=1 / 2$ for mature stages, $\phi=1 / 4$ for declining stages and $\phi=0$ for terminal stages.

The fundamental assumption underlying the icestream classification in Table 2 is that marine ice streams begin in inter-island channels on the outer edge of broad polar continental shelves or in the straits where large continental embayments open on to polar oceans. These continental shelves and embayments are sedimentary basins floored by permafrost at the beginning of a glaciation cycle, when sea ice thickens and grounds on the icecemented sediments, and continued thickening produces marine ice domes whose terrestrial margins transgress on to land and whose marine margins encroach on to the outer continental shelf (Denton and Hughes, 1981; Hughes, 1982, 1987a; Lindstrom and MacAyeal, 1987, 1989; Lindstrom, 1990). The life cycle of marine ice streams follows from this assumption.

Since the mass balance of an ice stream changes during its life cycle, pulling power $P_{x}$ should be computed for the actual mean ice velocity $\bar{u}_{x}$, not the velocity $u$ for mass-balance equilibrium given by Equation (17). An equation for $\bar{u}_{x}$ that is based on the basal buoyancy factor $\phi$ and combines mean sliding velocity $\bar{u}_{0}$ with mean creep velocity $\bar{u}_{\mathrm{c}}$ along length $L_{\mathrm{S}}$ of stream flow is:

$$
\begin{aligned}
\bar{u}_{x} & =\phi \bar{u}_{0}+(1-\phi) \bar{u}_{\mathrm{c}} \\
& =\phi\left(\bar{u}_{\mathrm{S}}+\int_{x}^{L_{\mathrm{S}}} \dot{\epsilon}_{x x} \mathrm{~d} x\right)+(1-\phi) \int_{0}^{h} \int_{0}^{z}\left(\dot{\epsilon}_{x z} / h\right) \mathrm{d} z \mathrm{~d} z
\end{aligned}
$$


Table 2. A life-cycle classification for ice streams*

\begin{tabular}{|c|c|c|c|c|c|c|c|c|c|c|c|}
\hline \multirow{6}{*}{ 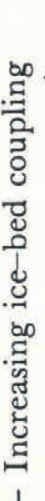 } & \multicolumn{5}{|c|}{ Stages in life cycle } & \multicolumn{2}{|l|}{ Stage } & \multicolumn{4}{|c|}{$\phi$ during life cycle } \\
\hline & $1 \mathrm{~A}$ & 1B & $1 \mathrm{C}$ & $1 \mathrm{D}$ & $1 \mathrm{E}$ & Inception & 1 & $3 / 4$ & $1 / 2$ & $1 / 4$ & 0 \\
\hline & $2 \mathrm{~A}$ & $2 B$ & $2 \mathrm{C}$ & $2 \mathrm{D}$ & $2 \mathrm{E}$ & Growth & $3 / 4$ & $3 / 4$ & $1 / 2$ & $1 / 4$ & 0 \\
\hline & $3 \mathrm{~A}$ & 3B & $3 \mathrm{C}$ & $3 \mathrm{D}$ & $3 \mathrm{E}$ & Mature & $1 / 2$ & $1 / 2$ & $1 / 2$ & $1 / 4$ & 0 \\
\hline & $4 \mathrm{~A}$ & $4 \mathrm{~B}$ & $4 \mathrm{C}$ & $4 \mathrm{D}$ & $4 \mathrm{E}$ & Declining & $1 / 4$ & $1 / 4$ & $1 / 4$ & $1 / 4$ & 0 \\
\hline & $5 \mathrm{~A}$ & $5 \mathrm{~B}$ & $5 \mathrm{C}$ & $5 \mathrm{D}$ & $5 \mathrm{E}$ & Terminal & 0 & 0 & 0 & 0 & 0 \\
\hline
\end{tabular}

Increasing ice-shelf buttressing $\rightarrow$

*Pulling power decreases from $1 \mathrm{~A}$ to $5 \mathrm{E}$ defined as:

1. Full basal buoyancy along entire length.

2. Basal buoyancy slowly decreasing upstream.

3. Basal buoyancy steadily decreasing upstream.

4. Basal buoyancy rapidly decreasing upstream.

5. No basal buoyancy along entire length.

A. No ice shelf or a freely floating ice shelf.

B. Weak buttressing by a confined and pinned ice shelf.

C. Moderate buttressing by a confined and pinned ice shelf.

D. Strong buttressing by a confined and pinned ice shelf.

E. Full buttressing by a confined and pinned ice shelf.

$$
\begin{gathered}
=\phi\left[\bar{u}_{\mathrm{S}}+\left(\rho_{\mathrm{I}} g / 4 \bar{A}\right)^{n}\left(1-\rho_{\mathrm{I}} / \rho_{\mathrm{W}}\right)^{n} \sum_{x}^{L_{\mathrm{S}}} h^{n} \Delta x\right] \\
+(1-\phi)\left[\left(\rho_{\mathrm{I}} g h \Delta h / \bar{A} \Delta x\right)^{n} h /(n+2)\right]
\end{gathered}
$$

where $\dot{\epsilon}_{x x}$ and $\dot{\epsilon}_{x z}$ are given by Equations (11) and (7), respectively. Equation (57) gives $\bar{u}_{x}$ for sheet flow when $\phi=0$ and $\bar{u}_{x}$ for shelf flow when $\phi=1$ and $L_{\mathrm{S}}=0$, so that $\bar{u}_{\mathrm{S}}$ becomes $\bar{u}_{\mathrm{G}}$, the mean ice velocity across the grounding line and $x$ is negative for floating ice. When $\bar{u}_{x}$ given by Equation (57) is multiplied by $F_{x}$ given by Equation (16), the resulting expression for pulling power $P_{x}$ is a complex function of basal buoyancy factor $\phi$.

From Equation (3), $\phi$ is a measure of ice-bed coupling. From Equation (21), $\phi$ is also a measure of ice-shelf buttressing. Therefore, a classification of ice streams for ice-bed coupling increasing from 1 to 5 and for ice-shelf buttressing increasing from $\mathrm{A}$ to $\mathrm{E}$ can be based on specifying $\phi$ along an ice stream.

\section{Inception stage of ice streams}

Marine ice accelerates as it enters inter-island channels and straits, where the bed is already thawed or becomes thawed by the increased basal frictional heat. Since the thawed bed consists of water-saturated sediments, 1A ice streams are nucleated in these channels and straits because ice-bed coupling is nil and only sea ice exists beyond the ice streams. The Wilkes Land margin of the
East Antarctic ice sheet has the most likely candidates for $1 \mathrm{~A}$ ice streams, notably Ninnis, Mertz, Totten and Vanderford Glaciers in Figure 1 (Hughes, 1987b).

\section{Growth stage of ice streams}

Basal frictional heat is concentrated at the heads of channels and straits, where basal traction is a maximum at the basal melting-point isotherm that separates frozen from thawed parts of the bed. This is a highly unstable condition because frictional heat causes the isotherm to retreat rapidly. A maximum-slope surface-inflection line marks the head of these ice streams and exists above the basal isotherm. Hence the ice streams retreat rapidly, drawing down the marine ice dome and thereby raising sea level. Rising sea level floats the grounding line of marine ice streams over the submarine sills that typically exist at the oceanward ends of channels and straits, causing an ice shelf to form as grounding lines retreat. The sills are either bedrock ridges or grounding-line moraines, and they form as the thawed sediments are eroded by the ice streams, causing bedrock to crop out on the bed in places where sediments were thin. This situation produces $1 \mathrm{~B}$ and $2 \mathrm{~A}$ ice streams, where grounding-line retreat provides increasing ice-shelf buttressing (1B ice streams) and bedrock cropping out provides increasing ice-bed coupling (2A ice streams). Pine Island Glacier and Thwaites Glacier are respective $1 \mathrm{~B}$, and $2 \mathrm{~A}$ or $2 \mathrm{~B}$ ice streams in the Pine Island Bay polynya of the Amundsen 
Sea embayment of the marine West Antarctic ice sheet (Hughes, 1981b; Lindstrom and Hughes, 1984).

\section{Mature stage of ice streams}

Pulling power of marine ice streams increases rapidly as grounding lines retreat downslope into the isostatically depressed marine sedimentary basins and decreases rapidly as grounding lines retreat upslope out of these basins, since the pulling force is greatest when the grounding line is furthest below sea level. Hence, the mature stage of marine ice streams exists when a floating ice shelf occupies the seaward half of a marine sedimentary basin and a grounded ice dome occupies the landward half, with ice streams drawing down the marine ice dome and eroding thawed marine sediments beneath the dome. This situation produces $1 \mathrm{C}, 2 \mathrm{C}, 3 \mathrm{C}, 3 \mathrm{~B}$ and $3 \mathrm{~A}$ ice streams, depending on the degree of ice-bed coupling and ice-shelf buttressing for ice streams at various sites in the embayment. The Ross Sea and Weddell Sea embayments of the marine West Antarctic ice sheet contain mature ice streams (Hughes, 1977).

\section{Declining stage of ice streams}

Retreating grounding lines of marine ice streams eventually stabilize when they lie in water too shallow to sustain a significant pulling force or lie against the headwalls of fiords through coastal mountains, while a floating ice shelf fills much of the marine sedimentary basin beyond the grounding line. Retreating inflection lines at the heads of ice streams can continue to retreat, pulling more ice into the marine basins and drawing down terrestrial ice domes. Marine ice streams become terrestrial ice streams at this stage, and they persist so long as accumulation over terrestrial ice domes replaces ice pulled out by stream flow. This loss of marine character is typical of $1 \mathrm{D}, 2 \mathrm{D}, 3 \mathrm{D}, 4 \mathrm{D}, 4 \mathrm{C}, 4 \mathrm{~B}$ and $4 \mathrm{~A}$ ice streams, and therefore represents the declining stage of marine ice streams. Outlet glaciers through the Transantarctic Mountains are probably 3D, 4D and 4C ice streams that drain the largely terrestrial East Antarctic ice sheet and are buttressed by ice shelves floating in the marine sedimentary basins of West Antarctica (Swithinbank, 1963).

\section{Terminal stage of ice streams}

When an ice stream is no longer able to deliver ice to the calving front of its ice shelf fast enough to offset the iceberg-calving rate, the ice stream enters its terminal stage. Ice streams are terminal in stages $1 \mathrm{E}, 2 \mathrm{E}, 3 \mathrm{E}, 4 \mathrm{E}$, $5 \mathrm{E}, 5 \mathrm{D}, 5 \mathrm{C}, 5 \mathrm{~B}$ and $5 \mathrm{~A}$. A calving bay carves away the ice shelf until its calving front coincides with its grounding line to produce a calving ice wall. A $5 \mathrm{E}$ ice stream ideally exists in a fiord floored by rugged bedrock, so that ice-bed coupling is optimized; and supplies an ice shelf grounded on all sides, so that ice-shelf buttressing is optimized. Lambert Glacier, which pulls terrestrial East Antarctic ice into the Amery Ice Shelf, may be a rejuvenated 5E ice stream (Allison, 1979; Hughes, 1987b). Rejuvenation of a $5 \mathrm{E}$ ice stream occurs when a calving bay reduces ice-shelf buttressing, converting it into an ice stream in stages moving from $5 \mathrm{E}$ to $5 \mathrm{~A}$, thereby causing a great increase of ice-stream velocity. This may be the case with Jakobshavns Isbræ that drains much of the west-central Greenland ice sheet into Jakobshavns Isfjord and is the fastest ice stream known (Hughes, 1986).

\section{Modeling ice-stream life cycles}

About $90 \%$ of the ice in present-day ice sheets covering Antarctica and Greenland is discharged by marine ice streams. If this was true of the marine margins of former ice sheets, and if terrestrial ice streams were prominent along their terrestrial margins, then computer models that simulate the advance and retreat history of ice sheets should include any proposed life cycle for ice streams. The life cycle for ice streams proposed here would apply to deglaciation episodes in the history of a marine ice sheet, if the marine ice-transgression hypothesis explains its glaciation episodes (Hughes, 1986). A marine ice sheet is postulated to form when sea ice thickens and grounds in shallow marine embayments or on shallow continental shelves fringed by islands. Examples are Hudson Bay, Foxe Basin and inter-island channels of the Queen Elizabeth Islands in North America, the Baltic, Barents and Kara Seas in Eurasia, Byrd Subglacial Basin and the Ross and Weddell Seas in Antarctica. Grounding occurs mainly on sediments in the permafrost condition, so that the marine ice sheet grows on a frozen bed that precludes formation of marine ice streams. When a marine ice sheet becomes thick enough to thaw the basal permafrost, both by depressing the basal melting point and increasing basal-friction heating, ice streams will develop in outer inter-island channels where most marine ice is discharged. This begins the deglaciation history of the marine ice sheet and the life cycle of its ice streams.

Computer models of ice sheets that include the life cycle of marine ice streams need to incorporate three boundary conditions that constrain stream flow: (1) iceshelf buttressing, (2) ice-bed coupling, and (3) side-shear traction. As defined by Equation (3), the basal buoyancy factor $\phi$ has potential for parameterizing the first two of these constraints, and the third constraint is made to depend on $\phi$ by way of Equation (46). The resulting expression for $\Delta h / \Delta x$ is Equation (49) and it includes the effects of all boundary conditions for specified values of $\phi$.

An empirical expression for $\phi$ that produces a $\phi$ spectrum close enough to the theoretical $\phi$ curves in Figure 5 to justify using it to simulate the life cycle of ice streams in computer models of ice-sheet dynamics is:

$$
\phi=\phi_{\mathrm{G}}\left(1-x / L_{\mathrm{S}}\right)^{c}
$$

where $c$ is a constant ranging from zero to infinity. Figure 10 is a plot of Equation (58) for comparison with Figure 5, showing that $c=\infty$ reproduces case I and $c=0$ reproduces case IV, the two end members of the $\phi$ spectrum. Case II is approximated by $c=1.0$ and case III is approximated by $c=0.1$. During the life cycle of an ice stream, $c$ increases from zero to infinity and $\phi_{\mathrm{G}}$ decreases from one to zero as time progresses, with $c$ representing ice-bed coupling and $\phi_{\mathrm{G}}$ representing ice-shelf buttressing along the various pathways depicted in Table 2.

Equation (49) can be integrated numerically to produce the changing profiles of ice streams during an ice- 


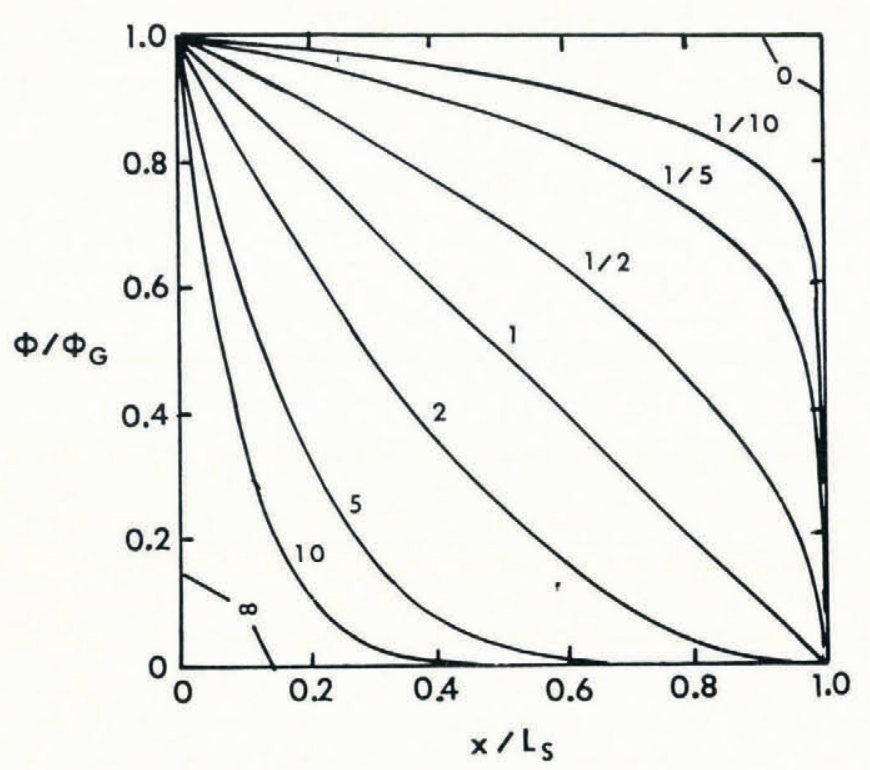

Fig. 10. The variation of ice-bed coupling $\phi / \phi_{\mathrm{G}}$ with distance $x$ upstream from the grounding line of a marine ice stream of length $L_{\mathrm{S}}$ for $\mathrm{c}$ values ranging from zero to infinity in Equation (58).

stream life cycle. If flowline length $L$ is divided into $i$ steps of constant length $\Delta x$ over which ice elevation increases by variable height $\Delta h=h_{i+1}-h_{i}$, where $i$ is an integer and stream flow occurs over length $L_{\mathrm{S}}$ of $L$, Equation (49) can then be written:

$$
\begin{aligned}
& h_{i+1}= \\
& h_{i}+\left\{\left\{h_{i} a-h_{i}^{2}\left[\frac{\rho_{\mathrm{I}} g h_{i}}{4 A}\left(1-\frac{\rho_{\mathrm{I}}}{\rho_{\mathrm{W}}}\right)-\frac{\left(\tau_{\mathrm{v}}\right)_{\mathrm{G}} x}{w A}\left(1-\frac{h_{\mathrm{G}}}{h}\right)\right]^{n}\right.\right. \\
&\left.\cdot\left[\left(1-\frac{x}{L_{\mathrm{S}}}\right)^{2 c} \phi_{\mathrm{G}}^{2}\right]^{n}\right\} /\left\{h_{\mathrm{G}} u_{\mathrm{G}}+a x\right\} \\
&+\left\{\left[\frac{(m+1) \rho_{\mathrm{I}} g a^{2} B^{2 m}(L-x)^{(2 m+1) / m}}{(2 m+1)\left[L^{(m+1) / m}-(L-x)^{(m+1) / m}\right]}\right.\right. \\
&\left.\left.\left.\cdot\left(1-\left(1-\frac{x}{L_{\mathrm{S}}}\right)^{4 m}\right)\right]^{1 /(2 m+1)}\right\} / \rho_{\mathrm{I}} g h_{i}\right\} \Delta x .
\end{aligned}
$$

Equation (59) can be numerically integrated directly using the Euler method or more accurately using the Runge-Kutta method. Ice--bed coupling is specified for $0 \leq c \leq \infty$ and ice-shelf buttressing is specified for $0 \leq$ $\phi_{\mathrm{G}} \leq 1$.

Ice-stream surface profiles constructed on a horizontal bed using Equation (59) are plotted in Figures 11 through 14 for $\rho_{\mathrm{I}}=960 \mathrm{~kg} \mathrm{~m}^{-3}, g=9.8 \mathrm{~m} \mathrm{~s}^{-2}$, $L=1000 \mathrm{~km}, L_{\mathrm{S}}=400 \mathrm{~km}, w=30 \mathrm{~km}, h_{\mathrm{G}}=$ $500 \mathrm{~m}, u_{\mathrm{G}}=1000 \mathrm{ma}^{-1}, m=2, n=3,\left(\tau_{\mathrm{v}}\right)_{\mathrm{G}}=$ $10 \mathrm{kPa}, B=2 \mathrm{kPa}^{\frac{1}{2}} \mathrm{~m}^{-\frac{1}{2}}$ (Hughes, 1981a) and $A=$ $470 \mathrm{a}^{\frac{1}{3}} \mathrm{kPa}\left(A^{-n}=3.16 \times 10^{-16} \mathrm{~s}^{-1} \mathrm{kPa}^{-3}\right)$ for a mean temperature of $-15^{\circ} \mathrm{C}$ through the ice thickness (Paterson, 1981, table 3.3).

Figure 11 shows the effect of ice-bed coupling for the midpoint value of ice-shelf buttressing, $\phi_{\mathrm{G}}=\frac{1}{2}$. Sur-

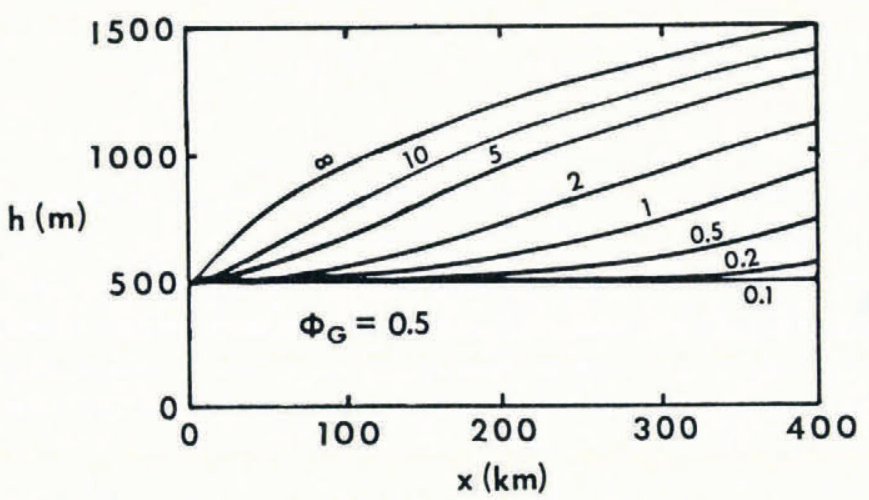

Fig. 11. Evolution of an ice flowline profile from convex sheet flow to concave stream flow as ice-bed coupling exponent c in Equation (58) decreases from infinity to zero for intermediate ice-shelf buttressing given by $\phi_{\mathrm{G}}=$ 0.5 .

face profiles are plotted for $c$ values of $0,1 / 10,1 / 5,1 / 2$, $1,2,5$ and 10, following the $c$ spectrum in Figure 10. The ice-stream surface elevation does not begin to climb along distance $x$ upstream from the grounding line until $c=1 / 5$, and the surface-inflection point separating lower concave parts from upper convex parts begins to migrate toward the grounding line when $c>1$, being at $240 \mathrm{~km}$ for $c=2,120 \mathrm{~km}$ for $c=5,80 \mathrm{~km}$ for $c=10$ and at the grounding line for $c=\infty$. Hence, the pulling power of the ice stream, as represented by a down-draw that creates a lowered concave surface reaches further and more strongly into the ice sheet as ice-bed coupling, represented by $c$, decreases.

Figure 12 shows an instability in the $c$ spectrum when

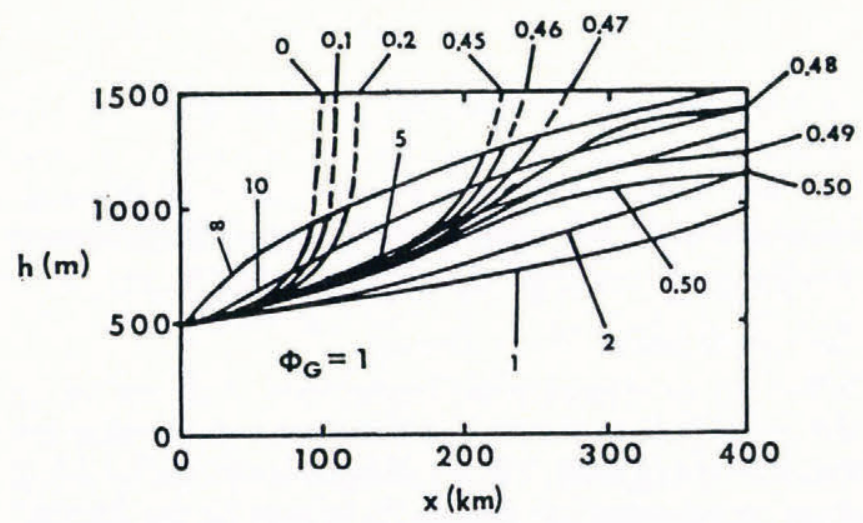

Fig. 12. The lengthening reach of a marine ice stream into an ice sheet during the inception and growth stages, shown as flowline profiles for various c values in Equation (58) when $\phi_{\mathrm{G}}=1$ specifies no ice-shelf buttressing. As c increases, the concave streamflow profile (excluding dashed parts of surfaceelevation curves) migrates toward the ice divide, with substantial down-draw of sheet flow occurring after a surface-inflection instability at $0.47<c<0.48$. Stream flow steadily reverts to sheet flow for $c>1$, causing the flowline elevation to increase and its profile to become increasingly convex. 


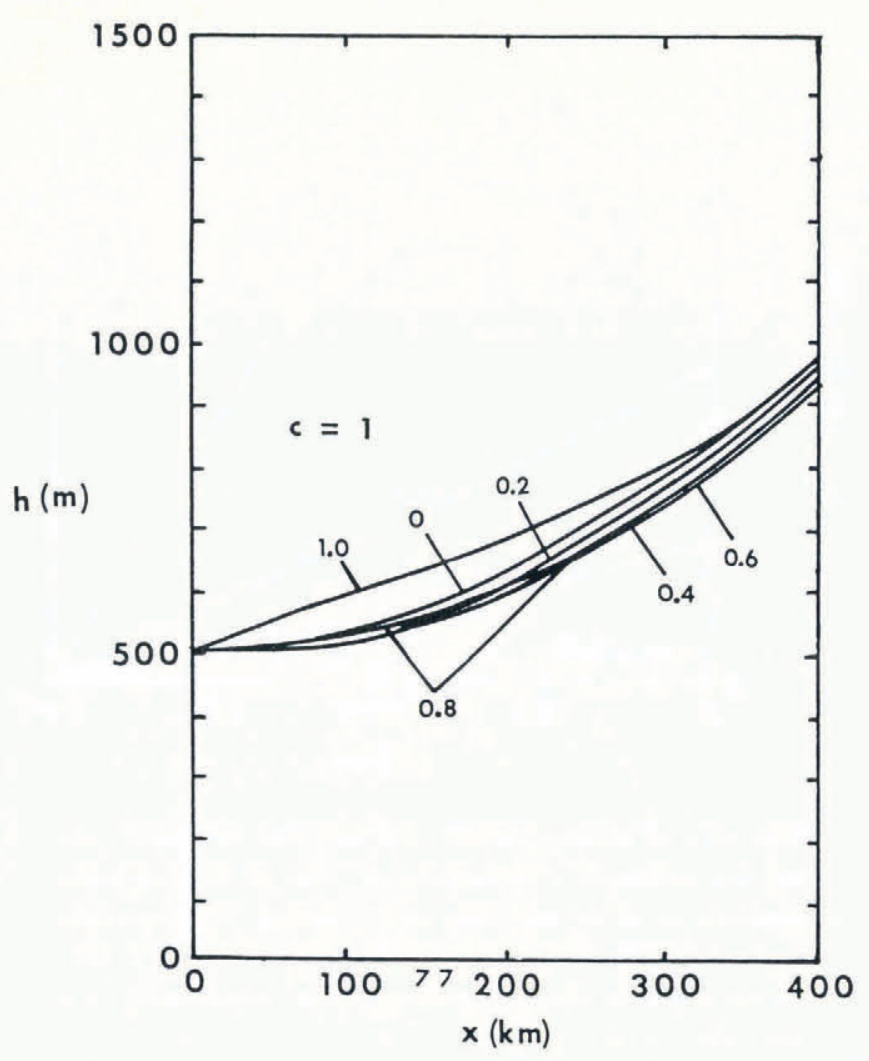

Fig. 13. Surface profiles of marine ice streams for ice-shelf buttressing increasing from no buttressing $\left(\phi_{\mathrm{G}}=1\right)$ to full buttressing $\left(\phi_{\mathrm{G}}=\right.$ $0)$ for moderate ice-bed coupling $(c=1)$. The lowest profiles are for moderate ice-shelf buttressing $\left(0.4<\phi_{\mathrm{G}}<0.6\right)$.



Fig. 14. Surface profiles of marine ice streams for ice-shelf buttressing increasing from no buttressing $\left(\phi_{\mathrm{G}}=1\right)$ to full buttressing ( $\phi_{\mathrm{G}}=$ $0)$ for low ice-bed coupling $(c=0.5)$. The concave surface of stream flow and the surface lowering of sheet flow develop most rapidly at the onset of ice-shelf buttressing $\left(1.00<\phi_{\mathrm{G}}<\right.$ $0.95)$.

$\phi_{\mathrm{G}}=1$ for no ice-shelf buttressing. The first righthand term in Equation (59) is the pulling term, as it contains $\sigma_{x x}^{\prime}$, and it takes charge as $c$ drops from 0.48 to 0.47 . For higher values of $c$, the upper part of the ice stream has a convex profile that first migrates upstream and then migrates downstream as $c$ increases, producing the wholly convex surface of sheet flow at $c=\infty$. For lower values of $c$, the lower part of the ice stream has a concave profile that moves toward the grounding line as $c$ decreases, and produces a concave surface for $c=0$ that intersects the convex surface for $c=\infty$ at $93 \mathrm{~km}$ from the grounding line and at an ice elevation of $930 \mathrm{~m}$.

Figure 13 shows the effect of ice-shelf buttressing for the midpoint value of ice-bed coupling $c=1$. Surface profiles are plotted for $\phi_{\mathrm{G}}$ values of $0,0.2,0.4$, 0.6, 0.8 and 1.0. All of these profiles are concave and they are nearly superimposed for the middle range of $0.2 \leq \phi_{\mathrm{G}} \leq 0.8$. The concave profiles are higher for $\phi_{\mathrm{G}}=0$, and especially for $\phi_{\mathrm{G}}=1$, because the surface elevation climbs close to the grounding line.

Figure 14 shows the effect of ice-shelf buttressing for less extensive ice-bed coupling represented by $c=\frac{1}{2}$. Values of $\phi_{\mathrm{G}}$ are $0,0.20,0.50,0.90,0.95$ and 1.00 to bring out the rapid upstream increase of ice elevation from $\phi_{\mathrm{G}}=0.95$ to $\phi_{\mathrm{G}}=1.00$, with a convex part developing as ice-shelf buttressing vanishes. The lowest icestream profile is for $\phi_{\mathrm{G}}=0.50$, the midpoint of ice-shelf buttressing.

\section{Pulling power drives the ice-stream life cycle}

The ice-stream pulling power obtained from Equation (18) is:

$$
\begin{aligned}
P_{x} & =F_{x} u_{x}=2 \sigma_{x x}^{\prime} w h u_{x} \\
& =2\left[\frac{1}{4} \rho_{\mathrm{I}} g h\left(1-\rho_{\mathrm{I}} / \rho_{\mathrm{W}}\right) \phi^{2}\right] w\left(h_{\mathrm{G}} u_{\mathrm{G}}+a x\right) \\
& =\frac{1}{2} \rho_{\mathrm{I}} g h w \phi_{\mathrm{G}}^{2}\left(1-x / L_{\mathrm{S}}\right)^{2 c}\left(1-\rho_{\mathrm{I}} / \rho_{\mathrm{W}}\right)\left(h_{\mathrm{G}} u_{\mathrm{G}}+a x\right)
\end{aligned}
$$

where $h$ is obtained from Equation (59) and disregarding accumulation or ablation rates along the ice stream:

$$
h u_{x}=h_{\mathrm{G}} u_{\mathrm{G}}+a x
$$

for conservation of volume flow under equilibrium conditions. Ideally, $u_{x}$ should be given by $\bar{u}_{x}$ in Equation (57), which also depends on $\phi$, but changes in height and length of an ice stream over time are slow enough to justify using Equation (61). Figures 15 through 18 plot $P_{x}$ versus $x$ using Equation (60) and various combinations of ice-bed coupling and ice-shelf buttressing. For convenience, $P_{x}$ is plotted as being positive, although $u_{x}$ would make it negative.

The inception stage in the life cycle of an ice stream 
is illustrated in Figure 15, for which $c=0.1$ for minimal ice-bed coupling and $\phi_{\mathrm{G}}$ decreases from unity to zero as ice-shelf buttressing increases. Inception of stream flow begins without ice-shelf buttressing, and when basal meltwater is produced from thawing permafrost at the head of the ice stream faster than it is discharged across the grounding line, so that the ice stream migrates into the ice sheet. Ideally, this is case IV with $\phi_{\mathrm{G}}=1$. Retreat of the head and lengthening of the body of the ice stream are too rapid for hydrostatic equilibrium to be established beneath the ice stream and for sheet flow to be down-drawn into the ice stream. Figure 15 shows

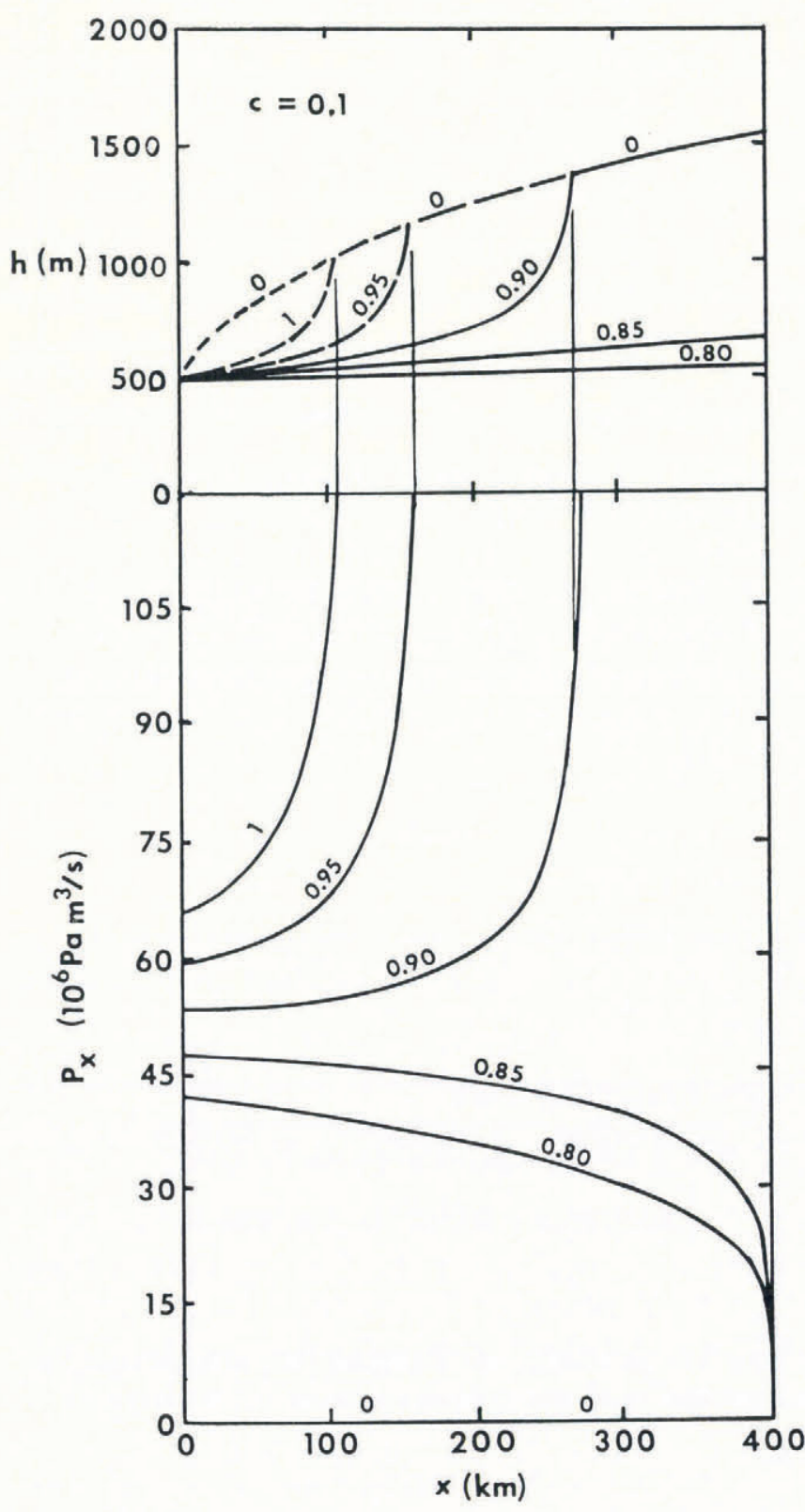

Fig. 15. Pulling power during the life cycle of an ice stream emphasizing the inception stage, with $c=0.1$ and $\phi_{\mathrm{G}}$ decreasing from unity to zero. As the ice stream retreats without concomitant down-draw of the ice sheet (top), pulling power is concentrated at the head of the ice stream (bottom). After down-draw begins for $\phi_{\mathrm{G}}<0.90$ (top), pulling power becomes greatest toward the foot of the ice stream (bottom).

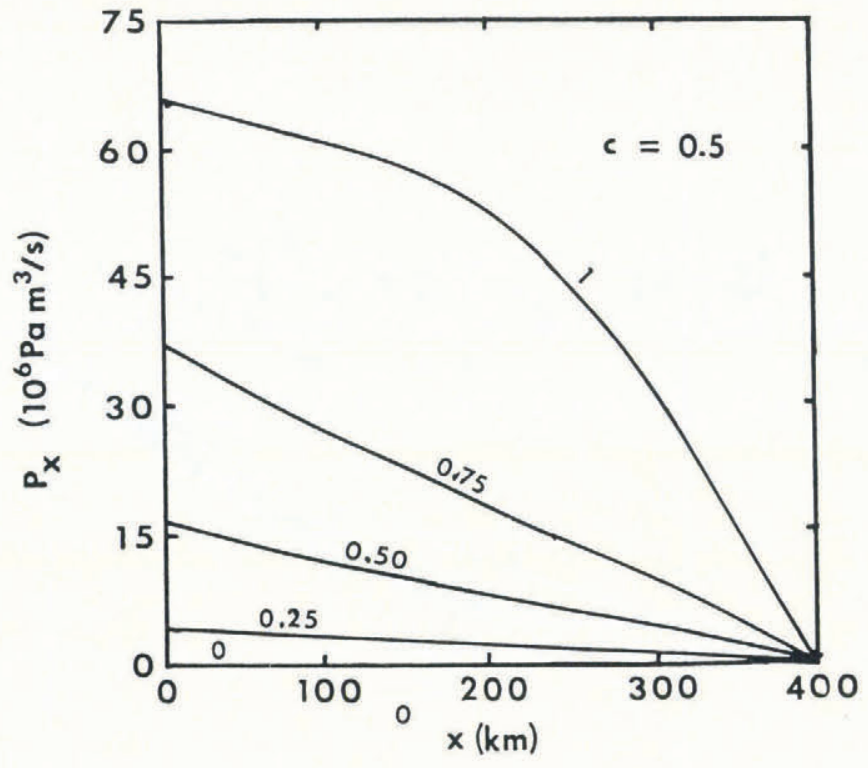

Fig. 16. Pulling power during the life cycle of an ice stream emphasizing the growth stage, with $c=0.5$ and $\phi_{\mathrm{G}}$ decreasing from unity to zero. Pulling power decreases slowly upstream from the grounding line, especially for the higher $\phi_{\mathrm{G}}$ values.

concave stream-flow surface profiles as retreating and lengthening over the range $1.00 \leq \phi_{\mathrm{G}} \leq 0.90$ (top), during which pulling power $P_{x}$ increases with distance upstream from the grounding line (bottom). The sheetflow surface profile, for which $\phi_{\mathrm{G}}=0$, is undisturbed beyond the ice stream. However, down-draw of sheet flow is dramatic over the range from $0.90 \leq \phi_{\mathrm{G}} \leq 0.85$ (top), during which $P_{x}$ changes dramatically from increasing to decreasing upstream from the grounding line (bottom). The conclusion to be drawn from this is that a little ice-shelf buttressing goes a long way in regulating both ice-stream retreat and ice-sheet down-draw when $h$ is formulated by Equation (59) and $P_{x}$ is formulated by Equation (60). In this formulation, the inception stage becomes the growth stage when $\phi_{\mathrm{G}}$ decreases from 0.90 to 0.85 and $c$ is nil.

An example of the growth stage in the ice-stream life cycle when $c=0.5$ is illustrated by Figure 16 . Pulling power is strongest at the grounding line and remains strong farther up the ice stream than for the other combinations of $c$ and $\phi_{\mathrm{G}}$ in Figures 16 through 18. Compared to the inception stage, pulling power reaches further into the ice sheet but pulls ice out with weaker grip during the growth stage. This is because hydrostatic equilibrium becomes established beneath the ice stream during the growth stage,

The mature stage in the ice-stream life cycle is represented by the combination $c=1, \phi_{\mathrm{G}}=0.75$ in Figure 17 . Pulling power remains strong at the grounding line because an ice shelf is providing only moderate buttressing. Pulling power decreases rapidly as $\phi_{\mathrm{G}}$ decreases.

Declining stages in the ice-stream life cycle are shown when $c=0.5,1,2$ are combined with $0.75>\phi_{\mathrm{G}}>0.25$ in Figures 16 through 18. The ice shelf has become somewhat confined in the embayment and pinned to islands or 


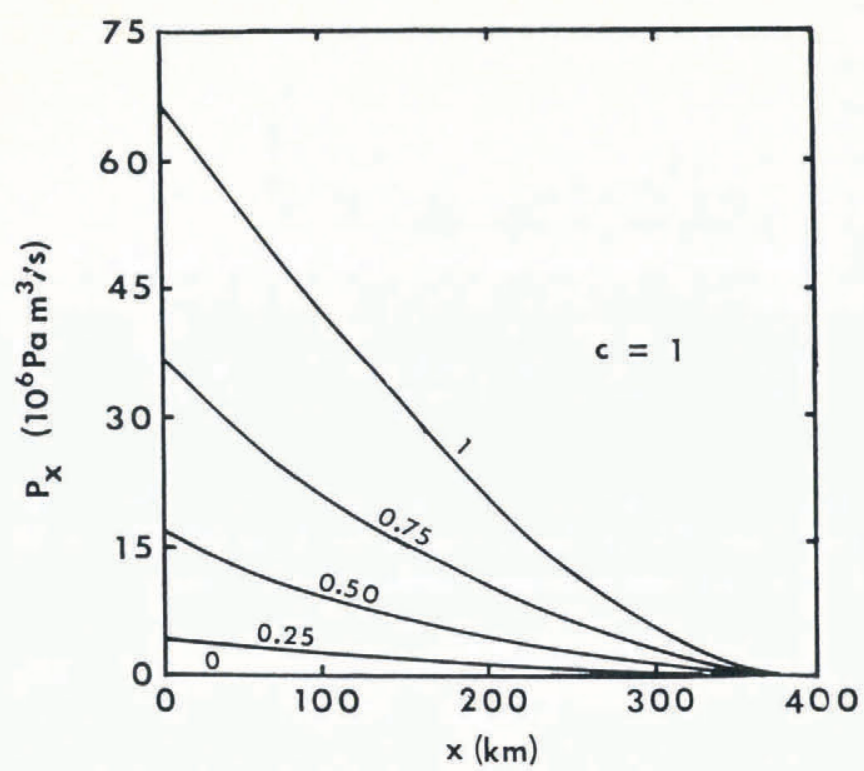

Fig. 17. Pulling power during the life cycle of an ice stream emphasizing the mature stage, with $c=1.0$ and $\phi_{\mathrm{G}}$ decreasing from unity to zero. Pulling power decreases steadily upstream from the grounding line, beginning at lower values as $\phi_{\mathrm{G}}$ decreases.

shoals, so pulling power at the grounding line has been reduced. It reaches up the ice stream with decreasing strength as ice-bed coupling increases.

Terminal stages in the ice-stream life cycle are approached most closely in Figures 16 through 18 when $c=0.5,1,2$ are combined with $\phi_{\mathrm{G}}<0.25$. The ice shelf is now both confined and pinned in an embayment studded with islands and shoals. Pulling power at the grounding line is so weak that the degree of ice-bed coupling upstream is relatively unimportant.

\section{PULLING POWER DISINTEGRATES MARINE ICE SHEETS}

The concept of a life cycle for marine ice streams in which pulling power is initially strong and remains strong upstream to the inflection line, as in $1 \mathrm{~A}$ ice streams, and becomes weaker and more concentrated near the grounding line, to terminate finally as a stagnant $5 \mathrm{E}$ ice stream, provides a blueprint for disintegration of marine ice sheets. Several mechanisms linked to pulling power contribute to disintegration.

The first mechanism is down-draw, which measures how far longitudinal pulling power can reach up an ice stream and into the heart of a marine ice sheet. The second mechanism is discerpation of ice ridges between ice streams by the transverse pulling power of these ice streams. The third mechanism is basal erosion caused by the pulling power of ice streams, so that stream flow migrates toward the ice divide of marine ice sheets. The fourth mechanism is creation and destruction of ice rises by pulling power, thereby controling the ability of an ice shelf to buttress marine ice streams. The fifth mechanism is widening ice streams by lateral pulling power, thereby enlarging the ice-stream drainage basin. The

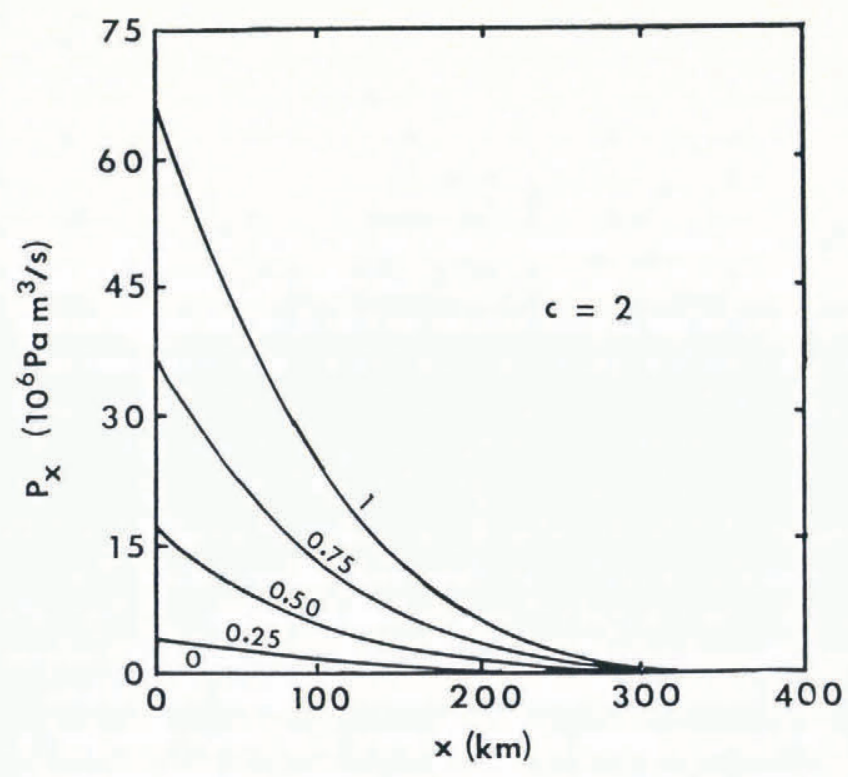

Fig. 18. Pulling power during the life cycle of an ice stream emphasizing the declining stage, with $c=2$ and $\phi_{\mathrm{G}}$ decreasing from unity to zero. Pulling power decreases rapidly upstream from the grounding line for larger $\phi_{\mathrm{G}}$ values and is low even at the grounding line for small $\phi_{\mathrm{G}}$ values. The terminal stages in the life cycle of an ice stream are represented by $\phi_{\mathrm{G}}=0$ in Figures 15 through 18, for which $P_{x}=0$.

sixth mechanism is ice-stream surges caused by intermittent increases in pulling power. These mechanisms will now be examined.

\section{Pulling power down-draws marine ice sheets}

Ice streams have surface profiles that reflect how far and how strong pulling power can reach up an ice stream and down-draw the ice sheet. The length of reach is controled by ice-bed coupling. The strength of reach is controled by ice-shelf buttressing.

The longest reach is provided by $c=0$ and the greatest strength is provided by $\phi_{\mathrm{G}}=1$ in Equations (59) and (60). Pulling power reaches full strength up the entire length $L_{\mathrm{S}}$ of the ice stream. This occurs during the inception stage, and produces stage $1 \mathrm{~A}$ ice streams. However, as shown in Figure 12, the concave part of stream flow is only about $93 \mathrm{~km}$ long and it is too early in the life cycle for interior ice to be down-drawn into the ice stream. Hence, the unlowered convex surface of sheet flow extends from there to the ice divide. There is no ice-bed coupling beneath the ice stream and no ice-shelf buttressing beyond the ice stream.

Down-draw begins during the growth stage of ice streams, when some sticky spots appear beneath ice streams and a confined or pinned ice shelf begins to form seaward of retreating ice-stream grounding lines. These conditions exist for $0<c<0.5$ and $0.75<\phi_{\mathrm{G}}<1.00$ in Equations (59) and (60). The reach and strength of pulling power are reduced, but the ice sheet is beginning to lower as interior ice is down-drawn into the ice streams. Surface profiles illustrating this situation are 
shown in Figure 14. Down-draw is greatest during the initial reduction of $\phi_{\mathrm{G}}$. That is, when the ice shelf becomes confined and pinned enough to cause some initial buttressing, weak as it is, as seen by the drastic drop in ice elevation from $\phi_{\mathrm{G}}=1.00$ to $\phi_{\mathrm{G}}=0.95$.

Down-draw stabilizes during the mature stage of ice streams, when sticky spots and slippery spots beneath the ice stream are in approximately equal abundance and the ice shelf beyond the ice stream floats in a large confining embayment, where it is pinned to islands or shoals at several points. This situation is represented by $c \approx 1$ and $\phi_{\mathrm{G}} \approx 0.75$ in Equations (59) and (60). Surface profiles of mature ice streams are shown in Figure 13. The instability of surface profiles depicted in Figure 12 over the narrow range $0.47<c<0.48$ when $\phi_{\mathrm{G}}=1$ vanishes quickly as $\phi_{\mathrm{G}}$ becomes smaller, and occurs at lower values of $\phi_{\mathrm{G}}$ for lower $c$ values, as seen in Figure 15. Whether this has any physical significance is unclear. Comparing Figures 13 and 14 shows that surface elevations at the head of the ice stream can be higher for the mature stage than for the growth stage in many cases. This reflects the steady reduction of pulling power from the growth stage to the mature stage. With less ice being pulled out through ice streams, interior ice elevations can stabilize and even recover.

Down-draw is absent during the declining stage of ice streams because their pulling power is too weak and too short in reach. The bed beneath the ice streams consists of slippery spots scattered in a sticky matrix and a confined and pinned ice shelf strongly buttresses the ice streams. Equations (59) and (60) produce these conditions for $1<c<\infty$ and $0.75<\phi_{\mathrm{G}}<0.25$, with the convex surface of sheet flow extending closer to the grounding line as $c$ decreases and $\phi_{\mathrm{G}}$ decreases.

Sheet flow reaches the grounding line at the terminal stage of ice streams, for which $c=\infty$ and $\phi_{\mathrm{G}}=0$ in Equations (59) and (60). With full ice-bed coupling and ice-shelf buttressing, pulling power vanishes because $\phi=$ 0 makes $F_{x}=0$ in Equation (60). The ice sheet thickens because $u_{x}$ in Equation (60) is too small to discharge ice as rapidly as it precipitates over the ice sheet.

\section{Pulling power discerps ice ridges}

Ice ridges lie between ice streams. Since transverse profiles are often steeper that longitudinal profiles on ice ridges, flow down the flanks into ice streams is usually faster than flow along the crest into an ice shelf. The longitudinal profile of an ice ridge can be computed from solutions of Equation $(39)$ at the head $\left(x=L_{\mathrm{S}}\right)$ and the foot $(x=0)$ of its flanking ice streams, since these are also boundaries of the ice ridge. The longitudinal profile is the ice divide for transverse flow into the flanking ice streams.

Equation (39) has simple solutions at $x=0$ and $x=$ $L_{\mathrm{S}}$. At $x=0, \sigma_{x y}$ is small compared to $\sigma_{x x}^{\prime}$ and $\sigma_{x z}=$ $\tau_{0}=0$. Equation (39) at $h=h_{\mathrm{G}}$ is then:

$$
\left(\frac{\Delta h}{\Delta x}\right)_{\mathrm{G}}=\frac{a}{u_{\mathrm{G}}}-\frac{h_{\mathrm{G}}}{u_{\mathrm{G}}}\left(\frac{\sigma_{x x}-\sigma_{z z}}{2 A}\right)_{\mathrm{G}}^{n} .
$$

Weertman (1957a) derived an expression for the longitudinal strain rate in freely floating ice having constant width, and if the ice-shelf back-stress $\sigma_{\mathrm{G}}$ at the ground- ing line is included (Thomas, 1977), it becomes:

$$
\dot{\epsilon}_{x x}=\left(\frac{\sigma_{x x}-\sigma_{z z}}{2 A}\right)_{\mathrm{G}}^{n}=\left[\frac{\rho_{\mathrm{I}} g h_{\mathrm{G}}}{4 A}\left(1-\frac{\rho_{\mathrm{I}}}{\rho_{\mathrm{W}}}\right)-\frac{\sigma_{\mathrm{G}}}{A}\right]^{n} .
$$

Equation (39), making use of Equations (21) and (63), is then:

$$
\left(\frac{\Delta h}{\Delta x}\right)_{\mathrm{G}}=\frac{a}{u_{\mathrm{G}}}-\frac{h_{\mathrm{G}}}{u_{\mathrm{G}}}\left[\frac{\rho_{\mathrm{I}} g h_{\mathrm{G}} \phi_{\mathrm{G}}}{4 A}\left(1-\frac{\rho_{\mathrm{I}}}{\rho_{\mathrm{W}}}\right)\right]^{n} .
$$

At $x=L_{\mathrm{S}}$, let $\sigma_{x x}^{\prime}=0$ and $\sigma_{x y} \ll \sigma_{x z}=\tau_{0}=\tau_{\mathrm{M}}$. Equation (39) is then replaced by Equation (25) with $h=h_{\mathrm{S}}$, because buoyancy vanishes at $x=L_{\mathrm{S}}$ :

$$
\left(\frac{\Delta h}{\Delta x}\right)_{\mathrm{S}}=\frac{\tau_{0}}{\rho_{\mathrm{I}} g h_{\mathrm{S}}}
$$

where $\tau_{0}$ is given by Equation (28).

It is reasonable to assume that progressive ice-bed coupling from $x=0$ to $x=L_{\mathrm{S}}$ causes Equation (64) to be replaced gradually by Equation (65). One way to accomplish this is to write:

$$
\begin{aligned}
\frac{\Delta h}{\Delta x}= & \left(\frac{\Delta h}{\Delta x}\right)_{\mathrm{G}} \cos ^{2}\left(\frac{\pi x}{2 L_{\mathrm{S}}}\right)+\left(\frac{\Delta h}{\Delta x}\right)_{\mathrm{S}} \sin ^{2}\left(\frac{\pi x}{2 L_{\mathrm{S}}}\right) \\
= & {\left[\frac{a}{u_{\mathrm{G}}}-\frac{h_{\mathrm{G}}}{u_{\mathrm{G}}}\left(\frac{\rho_{\mathrm{I}} g h_{\mathrm{G}} \phi_{\mathrm{G}}}{4 A}\right)^{n}\left(1-\frac{\rho_{\mathrm{I}}}{\rho_{\mathrm{W}}}\right)^{n}\right] } \\
& \cdot \cos ^{2}\left(\frac{\pi x}{2 L_{\mathrm{S}}}\right)+\left[\frac{\tau_{0}}{\rho_{\mathrm{I}} g h_{\mathrm{S}}}\right] \sin ^{2}\left(\frac{\pi x}{2 L_{\mathrm{S}}}\right) \\
= & \left(\frac{2 \tau_{\mathrm{S}}}{\rho_{\mathrm{I}} g w}\right)_{\mathrm{G}} \cos ^{2}\left(\frac{\pi x}{2 L_{\mathrm{S}}}\right)+\left(\frac{\tau_{0}}{\rho_{\mathrm{I}} g h}\right)_{\mathrm{S}} \sin ^{2}\left(\frac{\pi x}{2 L_{\mathrm{S}}}\right) .
\end{aligned}
$$

In Equation (66), $\tau_{\mathrm{S}}$ is evaluated at the grounding line, where $\tau_{0}=\Delta \sigma_{x x} / \Delta x=0$ in Equation (14), so equating these equations requires that:

$$
\tau_{\mathrm{S}}=\frac{\rho_{\mathrm{I}} g w}{2}\left[\frac{a}{u_{\mathrm{G}}}-\frac{h_{\mathrm{G}}}{u_{\mathrm{G}}}\left(\frac{\rho_{\mathrm{I}} g h_{\mathrm{G}} \phi_{\mathrm{G}}}{4 A}\right)^{n}\left(1-\frac{\rho_{\mathrm{I}}}{\rho_{\mathrm{W}}}\right)\right]
$$

where $\tau_{\mathrm{S}}$ is the side-shear stress between an ice stream and its flanking ice ridge. Equation (66) is, of course, purely arbitrary. However, it has the virtue of illustrating that the pulling force $F_{x}$ defined by Equation (16) controls $\Delta h / \Delta x$ at $x=0$, and that the contribution to $\Delta h / \Delta x$ by $F_{x}$ decreases to zero at $x=L_{\mathrm{S}}$ in the same way that $\phi$ decreases in Equation (51).

A feature of the concave stream-flow profile given by Equation (66) is that it becomes a convex ridge-flow profile if:

$$
\tau_{0}=\rho_{\mathrm{I}} g h_{\mathrm{S}}\left[\frac{a}{u_{\mathrm{G}}}-\frac{h_{\mathrm{G}}}{u_{\mathrm{G}}}\left(\frac{\rho_{\mathrm{I}} g h_{\mathrm{G}} \phi_{\mathrm{G}}}{4 A}\right)^{n}\left(1-\frac{\rho_{\mathrm{I}}}{\rho_{\mathrm{W}}}\right)^{n}\right]
$$

so that Equation (25) becomes:

$$
\frac{\Delta h}{\Delta x}=\frac{h_{\mathrm{S}}}{h}\left[\frac{a}{u_{\mathrm{G}}}-\frac{h_{\mathrm{G}}}{u_{\mathrm{G}}}\left(\frac{\rho_{\mathrm{I}} g h_{\mathrm{G}} \phi_{\mathrm{G}}}{4 A}\right)^{n}\left(1-\frac{\rho_{\mathrm{I}}}{\rho_{\mathrm{W}}}\right)^{n}\right] .
$$

Since $\tau_{0}$ is constant along $x$ in Equation (68), Equat- 
ion (69) can be integrated to give the parabolic-surface profile that is predicted by plasticity theory:

$$
h=\left[h_{\mathrm{G}}^{2}+\left(2 \tau_{0} / \rho_{\mathrm{I}} g\right) x\right]^{\frac{1}{2}} .
$$

Equation (70) gives a parabolic ice-ridge profile when $\tau_{0}$ is given by Equation (68).

Comparing Equation (67) for $\tau_{\mathrm{S}}$ alongside an ice stream with Equation (68) for $\tau_{0}$ beneath an ice ridge having no basal buoyancy shows that side traction exceeds basal traction for unit traction area of an ice ridge, because:

$$
\tau_{0}=2\left(h_{\mathrm{S}} / w\right) \tau_{\mathrm{S}}
$$

where $w \gg h_{\mathrm{S}}$. The ice ridge will become part of its flanking ice streams when total side traction equals total basal traction for an ice ridge, so that $\tau_{0} L_{\mathrm{S}} W=2 \tau_{\mathrm{S}} L_{\mathrm{S}} H$, where $H$ is the mean side height of the ice ridge above its bed and $W$ is the width of the ice ridge. Hence, $W$ is the minimum spacing between ice streams and, for equal basal and side traction and $H \approx \frac{1}{2}\left(h_{\mathrm{G}}+h_{\mathrm{S}}\right)$ :

$$
W=2 H\left(\tau_{\mathrm{S}} / \tau_{0}\right)=\left(w / 2 h_{\mathrm{S}}\right)\left(h_{\mathrm{G}}+h_{\mathrm{S}}\right) .
$$

Examples of how ice-stream pulling power discerps intervening ice ridges are found along the West Antarctic grounding line of the Ross Ice Shelf, particularly the Siple Coast, where Whillans and others (1987) have measured surface velocities and deformation, and Shabtaie and others (1987) have mapped surface and basal topography (see Fig. 1). Ice ridge $\mathrm{AB}$ has a contorted surface similar to that of its flanking Ice Streams A and $\mathrm{B}$, whereas ice ridge $\mathrm{BC}$ has a smooth surface similar to Ice Stream C, which flanks it on the north. All three ice streams have surfaces not far above buoyancy along much of their length, with Ice Stream B underlain by deforming sediments (Blankenship and others, 1966), and much basal water along Ice Stream C (Robin and others, 1970). Ice Streams A and B move rapidly, inland ice augments local accumulation to give ice ridge $\mathrm{AB}$ a moderate velocity, inland ice is diverted into Ice Streams B and $\mathrm{C}$ by a local ice dome on ice ridge $\mathrm{BC}$, giving it a slow velocity from local accumulation only, and Ice Stream C scarcely moves at all (Whillans and others, 1987). From these observations, Ice Streams A and B are type $1 \mathrm{C}$ or $2 \mathrm{C}$, whereas Ice Stream $\mathrm{C}$ is type $1 \mathrm{E}$ or $2 \mathrm{E}$, being almost fully buttressed by the Ross Ice Shelf. Hence, Ice Streams A and B exert strong transverse pulling forces but Ice Stream C does not. Moreover, transverse ice velocity entering these ice streams is much higher from ice ridge $\mathrm{AB}$ than from ice ridge $\mathrm{BC}$. Ice ridge $\mathrm{AB}$ is therefore discerped by pulling power, whereas ice ridge $\mathrm{BC}$ is not, so ice ridge $\mathrm{AB}$ has the contorted pulled-apart surface of an ice stream, whereas ice ridge BC has a smooth surface.

\section{Pulling power measures the erosive power of ice streams}

Subglacial erosion requires a pulling force to loosen basal material and an ice velocity to transport the loosened material. Pulling power, being the product of this force and velocity, is a direct measure of the erosive capacity of an ice stream. Therefore, classifying ice streams accord- ing to pulling power provides a framework for answering the question posed by Bader (1961) as to whether an ice stream is likely to create its own subglacial depression. If stream flow develops independently of bed topography and if pulling power can migrate upstream, the ice stream will erode a linear basal depression. Flow converging downslope from saddles on the ice divide should be able to produce an ice stream without a trough in the bed. However, pulling power at the head of an ice stream co-exists with a peak in basal shear stress, so the bed should be strongly eroded beneath the surfaceinflection line. Retreat of the inflection line will be at a velocity that equals the erosion rate, and will produce a trough beneath the ice stream. The trough should form most rapidly for a $1 \mathrm{~A}$ ice stream, because basal erosion is merely a consequence of thawing ice-cemented permafrost, and most slowly for a 4D ice stream, because basal erosion requires quarrying bedrock. In short, the greater its pulling power, the more easily an ice stream can erode a trough.

Pulling power also allows an assessment of the hypothesis by Bader (1961) that an ice stream is selfperpetuating once it forms, because ice viscosity is lowered by the heat of internal friction. Frictional heat per unit area is generated by basal traction, and is greatest for a $5 \mathrm{~A}$ ice stream, which has minimal basal buoyancy and ice-shelf buttressing. Frictional heat per unit volume is generated by side traction, which is greatest for a $1 \mathrm{~A}$ ice stream, which has maximum basal buoyancy and minimum ice-shelf buttressing. Basal and side traction combine not only to reduce effective viscosity along these boundaries by generating easy-glide ice fabrics, but also to produce fiord-like channels by basal and side erosion. Both processes tend to stabilize the ice stream, making it self-perpetuating, and thereby allowing long-term erosion.

An early stage in channel formation might be taking place at the head of Ice Stream B on the Siple Coast of West Antarctica. Whillans and others (1987) reported that the head of Ice Stream B is a region where "rafts" of inland ice are being pulled into the ice stream. This is a region of converging flow, where the bed may be a mosaic of frozen and thawed patches that constitutes a transition from sheet flow over frozen permafrost to stream flow over thawed permafrost. If the "rafts" of relatively undeformed ice exist over frozen patches of permafrost, disintegration of the converging flow zone may proceed because pulling power is a maximum and can tear out these ice rafts. Peak pulling power plucks!

\section{Pulling power may regulate ice-shelf buttressing} Ice shelves are able to buttress ice streams because they exert form drag and dynamic drag (MacAyeal, 1987), largely because of ice rises, where ice shelves are locally grounded. Crary Ice Rise is a complex of local ice domes on the Ross Ice Shelf that has been variously described as becoming grounded or ungrounded from a ridge on the Ross Sea floor (MacAyeal and others, 1987). This bedrock ridge seems to continue ice ridge AB separating West Antarctic Ice Streams A and B (Bentley, 1984). It may therefore represent an advanced stage of disintegration of ice ridge AB. However, it also lies immediately downstream from Ice Stream B, which is car- 
rying several "rafts" of relatively thick and undeformed ice on to the Ross Ice Shelf. Whillans and others (1987) traced these "rafts" to high-stress regions at the head of Ice Stream B, notably the "Unicorn" where Ice Stream B forks into branches B1 and B2. This suggests that the Crary Ice Rise complex resulted from the pile-up of ice rafts against the bedrock ridge. In that case, Crary Ice Rise was created by pulling power disintegrating the head of Ice Stream B. Moreover, pulling power may be disintegrating Crary Ice Rise by plucking rafts of ice from its sides and lee end. Hence, pulling power may both create and destroy certain kinds of ice rises. These ice rises are temporary docking sites for ice rafts discharged on to ice shelves by ice streams. Pulling power regulates ice-shelf buttressing for these kinds of ice rises.

\section{Pulling power widens ice streams}

Ice Stream A supplies the southernmost corner of the Ross Ice Shelf, and it forms from the confluence of East Antarctic ice from Reedy Glacier and West Antarctic ice from Horlick Ice Stream. Some East Antarctic ice also enters Horlick Ice Stream from Shimizu Ice Stream and local ice from the Wisconsin Range supplies the head of Ice Stream A, in addition to its branches into East and West Antarctica.

Radio-echo sounding by Shabtaie and others (1987) showed that the lateral shear zones defining the sides of Ice Stream A lie about midway between two channels, a deep narrow channel along the center of a shallow wide channel. The deep narrow channel is presumably a fiord that turns southward beneath Reedy Glacier into East Antarctica, where it ends at a headwall in the Transantarctic Mountains. The wide shallow channel may have been eroded in ice-cemented sediments that form a mantle of permafrost over the bedrock of West Antarctica. The deep narrow channel would have been cut by East Antarctic ice from Reedy Glacier at a time when the West Antarctic ice sheet was much smaller than today or was absent. The shallow wide channel would have formed when the West Antarctic ice sheet was much larger than today, so that increased discharge from Horlick Ice Stream thawed the permafrost and eroded the sediments.

The fact that Ice Stream A has a width today that lies between the deep and shallow channels suggests that it is narrowing as West Antarctic ice lowers from its elevation at the last glacial maximum. Narrowing would then be a consequence of decreased pulling power as Ice Stream A ages from a mature $3 \mathrm{C}$ stage to a terminal $5 \mathrm{E}$ stage. Renewed growth of West Antarctic ice or, conversely, disintegration of the Ross Ice Shelf would increase pulling power and widen Ice Stream A. As Equation (72) shows, ice streams widen as they steepen, since $W / w$ decreases when $h_{\mathrm{G}} / h_{\mathrm{S}}$ decreases.

\section{Pulling power causes ice streams to surge}

As Bader (1961) observed, "An ice stream is something akin to a mountain glacier ... but a mountain glacier is laterally hemmed in by rock slopes, while the ice stream is contained by slower moving surrounding ice." Some mountain glaciers surge periodically, so periodic surges of ice streams should also be possible. Indeed, the Dibble and Dalton Iceberg Tongues grounded for $100 \mathrm{~km}$ on the continental shelf beyond unimpressive present-day ice streams in Wilkes Land, East Antarctica, may have formed when these ice streams surged, and Thwaites Glacier in Pine Island Bay, West Antarctica, may now be surging (see Fig. 1). Pulling power first increases and then decreases during a surge cycle, as both surface slope and ice velocity increase and decrease at the head of the mountain glacier or ice stream, where the surge begins, probably in phase with increases and decreases of basal buoyancy (Kamb and others, 1985).

If basal buoyancy, and therefore pulling power, controls surges of marine ice streams, surges can be triggered by rising sea level when the grounding line retreats faster than the inflection line. Rising sea level that moves the grounding line closer to the inflection line, thereby increasing surface slope, also lifts the ice shelf off its pinning points, thereby decreasing buttressing. Both processes increase the pulling power of the ice stream. As more ice is pulled out, the inflection line must retreat and pulling power extends its reach into the ice sheet. A $5 \mathrm{E}$ ice stream is most sensitive to changing sea level because basal buoyancy and ice-shelf buttressing change most dramatically at the grounding line. In contrast, a $1 \mathrm{~A}$ ice stream is least sensitive to changing sea level because no ice shelf buttresses its grounding line and full buoyancy extends back to its inflection line. There may be a natural evolution from a $1 \mathrm{~A}$ to a $5 \mathrm{E}$ ice stream, provided that a $1 \mathrm{~A}$ ice stream can erode its thawed basal sediments down to bedrock and its actively retreating inflection line can drag along its grounding line, to leave behind a buttressing ice shelf.

Table 3 compares the surface-slope expressions for sheet flow and ridge flow with those for stream flow having ice-bed coupling conditions specified by basal buoyancy factor $\phi$. Inception, growth, mature, declining and terminal stages of an ice-stream surge may mirror these stages for the life cycle of an ice stream by having a similar dependence on $\phi$ through time that includes the $\phi$ variations in Table 3 . The $\Delta h / \Delta x$ expression for stream flow for minimum basal buoyancy is different from Equation (30), the $\Delta h / \Delta x$ expression for case I, because their derivations were different. However, the $\Delta h / \Delta x$ expressions in cases II, III and IV in Equations (52), (54) and (56) for decreasing equilibrium and maximum basal buoyancy were based on the $\Delta h / \Delta x$ expression in Table 3. Note that $\left(\tau_{\mathrm{v}}\right)_{\mathrm{G}}=0$ when $\phi=0$.

\section{DISCUSSION}

Bader (1961) wondered whether "the ice stream, once started, is self-perpetuating because its mass, warmed up by heat of internal friction, has a lower viscosity than the surrounding ice." This lower viscosity need not exist in the bulk of the ice stream, only in its side and basal boundary zones, where frictional heating can substantially decouple the ice stream from flanking ice ridges and the bed, and where laminar flow might produce an easy-glide ice fabric. A question not asked by Bader (1961) is "How do ice streams start in the first place?" The answer to this question is part of "Glaciology's grand unsolved problem" posed by Weertman (1976).

An attempt at answering this question was to suggest that ice streams were a natural consequence of thermal convection in polar ice sheets, as horizontal advec- 
Sheet flow:

$$
\frac{\Delta h}{\Delta x}=\frac{\tau_{0}(x)}{\rho_{\mathrm{I}} g h}
$$

Ridge flow:

$$
\frac{\Delta h}{\Delta x}=\frac{h_{\mathrm{S}}}{h}\left[\frac{a}{u_{\mathrm{G}}}-\frac{h_{\mathrm{G}}}{u_{\mathrm{G}}}\left(\frac{\phi_{\mathrm{G}} \rho_{\mathrm{I}} g h_{\mathrm{G}}}{4 A}\right)^{n}\left(1-\frac{\rho_{\mathrm{I}}}{\rho_{\mathrm{W}}}\right)^{n}\right]
$$

Stream flow:

$$
\frac{\Delta h}{\Delta x}=\frac{h a-h^{2}\left[\left(\frac{\rho_{\mathrm{I}} g h}{4 A}\right)\left(1-\frac{\rho_{\mathrm{I}}}{\rho_{\mathrm{W}}}\right) \phi^{2}-\frac{\left(\tau_{\mathrm{v}}\right)_{\mathrm{G}}}{w A}\left(1+\frac{h_{\mathrm{G}}}{h}\right) \phi^{2} x\right]^{n}}{h_{\mathrm{G}} u_{\mathrm{G}}+a x}+\frac{\tau_{\mathrm{M}}}{\rho_{\mathrm{I}} g h}\left(1-\frac{\phi}{\phi_{\mathrm{G}}}\right)^{4 m /(2 m+1)}
$$

tion of ice toward the ice-sheet margin increasingly modified vertical convection of ice (Hughes, 1976). Being warmed by internal frictional heat, the ice stream would by buoyed upward, thereby decoupling it from the bed and allowing stream flow. A more plausible alternative is that stream flow begins when the cold-ice ceiling collapses into the warm-ice basement of a polar ice sheet, creating the concave longitudinal and transverse profiles that characterize stream flow. This is somewhat analogous to the cold lithosphere descending into the warm aesthenosphere of the Earth's mantle to produce crustal trenches. Polar ice sheets are like a miniature mantle in this respect, the major difference being that advection of ice from interior domes toward the margin compels ice-sheet "trenches" to form near the margin and move toward the margin as ice streams. Being partly collapsed "ceiling" ice, ice streams are colder than flanking uncollapsed ice, but they are also thinner than flanking ice so that basal meltwater is driven toward ice streams by the hydrostatic pressure gradient. It is this continuous supply of meltwater beneath ice streams that uncouples them from the bed enough to allow stream flow to start. This process would actually prevent thermal convection in ice streams, because the return cycle of convective flow, which ordinarily would allow thermal convection cells or rolls to develop, is short-circuited by advective flow, so that ice is re-routed through ice streams to the ice margin, never to return. In a sense, this is aborted thermal convection of the kind that can be initiated, but not sustained (Hughes, 1985).

Comparing vertical temperature profiles just above and below the sheet-flow to stream-flow transition, and in the flanking ice ridges, might determine if collapse of ceiling ice takes place. The ratio of cold ceiling ice to warm basement ice should be greatest in the ice stream. Ice Stream B, located in Figure 1, would be suitable for this experiment, since it is already being studied in detail.
Although this analysis of pulling power was focused on marine ice streams, it can be generalized to include terrestrial ice streams. This can be done through the basal buoyancy factor $\phi$. Ice-bed coupling for marine and terrestrial ice streams should have the same range, perhaps with total uncoupling being somewhat less likely for terrestrial ice streams, because drainage of basal meltwater around the perimenter of their terminal ice lobes is possible. Ice-lobe buttressing is similar to ice-shelf buttressing, where back-stress $\phi_{\mathrm{G}}$ is at the grounding line for an ice shelf and at the minimum-slope inflection line for an ice lobe.

The simplest braking force provided by an ice shelf of constant width $w$, grounded along both sides of floating length $L_{\mathrm{F}}$, and pinned by an island or shoal having transverse diameter $D$, is:

$$
F_{\mathrm{B}}=\sigma_{\mathrm{G}} w h_{\mathrm{G}}=2 \tau_{\mathrm{S}} \bar{h} L_{\mathrm{F}}+\sigma_{\mathrm{c}} \bar{h} D
$$

where $h_{\mathrm{G}}$ is grounding-line ice thickness, $\bar{h}$ is the average ice-shelf thickness, $\tau_{\mathrm{S}}$ is side-shear stress alongside $L_{\mathrm{F}}$ and $\sigma_{\mathrm{c}}$ is longitudinal compressive stress pushing against $D$. The simplest braking force provided by an ice lobe of constant width $w$ and grounded length $L_{\mathrm{G}}$ is:

$$
F_{\mathrm{B}}=\sigma_{\mathrm{G}} w h_{\mathrm{G}}=\tau_{0} w L_{\mathrm{G}}
$$

where $h_{\mathrm{G}}$ is the grounded ice thickness where the lobe begins and $\tau_{0}$ is the basal shear stress beneath the lobe.

Solving Equations (73) and (74) for $\sigma_{\mathrm{G}}$ gives expressions for $\sigma_{\mathrm{G}}$ in Equation (21) that allows $\phi_{\mathrm{G}}$ to be computed for an ice shelf and an ice lobe having these simple configurations. These values of $\phi_{\mathrm{G}}$ can then be used in Equation (3) to compute $\phi$ for buttressing of a marine ice stream by an ice shelf or a terrestrial ice stream by an ice lobe, for these simple configurations. In general, therefore, ice-bed coupling, ice-shelf buttressing and ice-lobe buttressing can be used to compute the basal buoyancy factor $\phi$ for any ice stream, marine or terrestrial. 


\section{ACKNOWLEDGEMENTS}

For me, Charles Swithinbank is the Father of Ice Streams, for his pioneering work on Antarctic outlet glaciers supplying the Ross Ice Shelf (Swithinbank, 1963). On one of them, Byrd Glacier, he revealed Swithinbank's law to me: "All knowledge is obvious - once you have found it out." This work is dedicated to him and the pursuit of his law. In my pursuit reported here, I became aware of another law: if something is obvious to me, but I cannot make it obvious to my readers, only one thing is obvious, it isn't obvious to me either.

I presented the germ of the pulling-power concept at the 1986 AGU Chapman Conference on Fast Glacier Flow. Since then I have become indebted to glaciologists on four continents who helped me to clarify and quantify the concept. In particular, I thank J. Fastook, who produced and plotted the numerical computations of surface profiles and pulling power for ice streams presented here, and R. Franzosa, for a mathematical analysis of the assumptions upon which these plots are based. These gentlemen will publish their own original work separately. Among editors and referees, G. Clarke, K. Echelmeyer, D. MacAyeal and C. Raymond have been particularly helpful. Most importantly of all, I thank B. Hughes for typing and processing seven versions of this manuscript for two journals. This work was funded by the U.S. National Science Fondation (grant DPP-8400886) and the U.S. Department of Energy (Battelle, PNL, subcontract 07112-A-B1).

\section{REFERENCES}

Alley, R. B. 1984. A non-steady ice sheet model incorporating longitudinal stresses. Ohio State Univ. Inst. Polar Stud. Rep. 84.

Alley, R. B. 1989a. Water-pressure coupling of sliding and bed deformation: I. Water system. J. Glaciol., 35(119), 108-118.

Alley, R.B. 1989b. Water-pressure coupling of sliding and bed deformation: II. Velocity-depth profiles. J. Glaciol., 35(119), 119-129.

Alley, R. B. and I. M. Whillans. 1984. Response of the East Antarctic ice sheet to sea-level rise. J. Geophys. Res., 89(C4), 6487-6493.

Alley, R. B., D. D. Blankenship, S. T. Rooney and C. R. Bentley. 1987. Till beneath Ice Stream B. 4. A coupled ice-till flow model. J. Geophys. Res., 92(B9), 89318940.

Allison, I. 1979. The mass budget of the Lambert Glacier drainage basin, Antarctica. J. Glaciol., 22(87), 223235.

Bader, H. 1961. The Greenland ice sheet. Hanover, NH, U.S. Army Cold Regions Research and Engineering Laboratory.

Bentley, C. R. 1984. The Ross Ice Shelf Geophysical and Glaciological Survey (RIGGS): introduction and summary of measurements performed. Antarct. Res. Ser., 42, 1-20.

Bindschadler, R. A. and R. Gore. 1982. A timedependent ice sheet model: preliminary results. J. Geophys. Res., 87(C12), 9675-9685.

Blankenship, D. D., C. R. Bentley, S. T. Rooney and R. B.
Alley, 1986. Seismic measurements reveal a saturated porous layer beneath an active Antarctic ice stream. Nature, 322(6074), 54-57.

British Glaciological Society. 1949. Joint meeting of the British Glaciological Society, the British Rheologists' Club and the Institute of Metals. J. Glaciol., 1(5), 231-240.

Budd, W.F., P. L. Keage and N. A. Blundy. 1979. Empirical studies of ice sliding. J. Glaciol., 23(89), 157170.

Denton, G.H. and T.J. Hughes, eds. 1981. The last great ice sheets. New York, etc., John Wiley and Sons.

Doake, C.S.M., R. M. Frolich, D. R. Mantripp, A. M. Smith and D. G. Vaughan. 1987. Glaciological studies on Rutford Ice Stream, Antarctica. J. Geophys. Res., 92(B9), 8951-8960.

Hughes, T.J. 1973. Is the West Antarctic ice sheet disintegrating? J. Geophys. Res., 78(33), 7884-7910.

Hughes, T. J. 1976. The theory of thermal convection in polar ice sheets. J. Glaciol., 16(74), 41-71.

Hughes, T.J. 1977. West Antarctic ice streams. Rev. Geophys. Space Phys., 15(1), 1-46.

Hughes, T. J. 1981a. Numerical reconstruction of paleoice sheets. In Denton, G. H. and T. J. Hughes, eds. The last great ice sheets. New York, etc., John Wiley and Sons, 221-261.

Hughes, T.J. 1981b. Correspondence. The weak underbelly of the West Antarctic ice sheet. J. Glaciol., 27(97), 518-525.

Hughes, T. J. 1982. Did the West Antarctic ice sheet create the East Antarctic ice sheet? Ann. Glaciol., 3, 138-145.

Hughes, T. J. 1985. Thermal convection in ice sheets: we look but do not see. J. Glaciol., 31(107), 39-48.

Hughes, T. J. 1986. The Jakobshavns effect. Geophys. Res. Lett., 13(1), 46-48.

Hughes, T.J. 1987a. Deluge II and the continent of doom: rising sea level and collapsing Antarctic ice. Boreas, 16(2), 89-100.

Hughes, T. J. 1987b. The marine ice transgression hypothesis. Geogr. Ann., 69A(2), 237-250.

Jezek, K. C. 1984. A modified theory of bottom crevasses used as a means for measuring the buttressing effect of ice shelves on inland ice sheets. J. Geophys. Res., 89(B3), 1925-1931.

Kamb, W.B. 1987. Glacier surge mechanism based on linked cavity configuration of the basal water conduit system. J. Geophys. Res., 92(B9), 9083-9100.

Kamb, W.B. and 7 others. 1985. Glacier surge mechanism: 1982-1983 surge of Variegated Glacier, Alaska. Science, 227(4686), 469-479.

Lindstrom, D. R. 1990. The Eurasian ice sheet: formation and collapse resulting from natural $\mathrm{CO}_{2}$ concentration variations. Paleoceanography, 5(2), 207-228.

Lindstrom, D. R. and T.J. Hughes. 1984. Downdraw of the Pine Island Bay drainage basins of the West Antarctic ice sheet. Antarct. J. U.S., 19(5), 56-58.

Lindstrom, D. R. and D.R. MacAyeal. 1987. Environmental constraints on West Antarctic ice-sheet formation. J. Glaciol., 33(115), 346-356. 
Lindstrom, D. R. and D. R. MacAyeal. 1989. Scandinavian, Siberian, and Arctic Ocean glaciation: effect of Holocene atmospheric $\mathrm{CO}_{2}$ variations. Science, 245(4918), 628-631.

Lindstrom, D. R. and D. Tyler. 1984. Preliminary results of Pine Island and Thwaites glaciers study. Antarct. J. U.S., 19(5), 53-55.

Lingle, C. S. and T. J. Brown. 1987. A subglacial aquifer bed model and water pressure dependent basal sliding relationship for a West Antarctic ice stream. In Van der Veen, C. J. and J. Oerlemans, eds. Dynamics of the West Antarctic ice sheet. Dordrecht, etc., D. Reidel Publishing Company, 249-285.

Lliboutry, L. 1958. Glacier mechanics in the perfect plasticity theory. J. Glaciol., 3(23), 162-169.

Lliboutry, L. 1987. Realistic, yet simple bottom boundary conditions for glaciers and ice sheets. J. Geophys. Res., 92(B9), 9101-9109.

MacAyeal, D. R. 1987. Ice-shelf backpressure: form drag versus dynamic drag. In Van der Veen, C. J. and J. Oerlemans, eds. Dynamics of the West Antarctic ice sheet. Dordrecht, etc., D. Reidel Publishing Company, 141-160.

MacAyeal, D. R. 1989. Large-scale ice flow over a viscous basal sediment: theory and application to Ice Stream B, Antarctica. J. Geophys. Res., 94(B4), 4071-4087.

MacAyeal, D. R., R.A. Bindschadler, S. Shabtaie, S. Stephenson and C.R. Bentley. 1987. Force, mass, and energy budgets of the Crary Ice Rise complex, Antarctica. J. Glaciol., 33(114), 218-230.

McInnes, B. J. and W.F. Budd. 1984. A cross-sectional model for West Antarctica. Ann. Glaciol., 5, 95-99.

Muszynski, I. 1987. The dynamics of coupled marine ice stream-ice shelf systems. (Ph.D. dissertation, Northwestern University, Evanston.)

Muszynski, I. and G. E. Birchfield. 1987. A coupled marine ice-stream-ice shelf model. J. Glaciol., 33(113), $3-15$.

Nye, J.F. 1952. A method of calculating the thicknesses of the ice-sheets. Nature, 169(4300), 529-530.

Nye, J. F. 1957. The distribution of stress and velocity in glaciers and ice-sheets. Proc. R. Soc. London, Ser. A, 239(1216), 113-133.

Nye, J.F. 1958. Comments on Professor Lliboutry's paper. J. Glaciol., 3(23), 170-172.

Oswald, G. K. A. and G. de Q. Robin. 1973. Lakes beneath the Antarctic ice sheet. Nature, 245(5423), 251-254.

Paterson, W. S. B. 1981. The physics of glaciers. Second edition. Oxford, etc., Pergamon Press.

Robin, G. de Q. 1967. Surface topography of ice sheets. Nature, 215(5105), 1029-1032.

Robin, G. de Q., C.W.M. Swithinbank and B.M.E. Smith. 1970. Radio echo exploration of the Antarctic ice sheet. International Association of Scientific Hydrology Publication 86 (ISAGE), 97-115.

Shabtaie, S. and C. R. Bentley. 1988. Ice-thickness map of the West Antarctic ice streams by radar sounding. Ann. Glaciol., 11, 126-136.
Shabtaie, S., I. M. Whillans and C. R. Bentley. 1987. The morphology of ice streams A, B, and C, West Antarctica, and their environs. J. Geophys. Res., 92(B9), 8865-8883.

Stuiver, M., G. H. Denton, T.J. Hughes and J. L. Fastook. 1981. History of the marine ice sheet in West Antarctica during the last glaciation: a working hypothesis. In Denton, G.H. and T. J. Hughes, eds. The last great ice sheet. New York, John Wiley and Sons, 319-436.

Swithinbank, C.W.M. 1963. Ice movement of valley glaciers flowing into the Ross Ice Shelf, Antarctica. Science, 141(3580), 523-524.

Thomas, R. H. 1977. Calving bay dynamics and ice sheet retreat up the St Lawrence valley systems. Géogr. Phys. Quat., 31(3-4), 347-356.

Thomas, R. H. and D. R. MacAyeal. 1982. Derived characteristics of the Ross Ice Shelf, Antarctica. J. Glaciol., 28(100), 397-412.

Van der Veen, C. J. 1987. Longitudinal stresses and basal sliding: a comparative study. In Van der Veen, C. J. and J. Oerlemans, eds. Dynamics of the West Antarctic ice sheet. Dordrecht, etc., D. Reidel Publishing Company, 223-248.

Van der Veen, C. J. and I. M. Whillans. 1989. Force budget: I. Theory and numerical methods. J. Glaciol., 35(119), 53-60.

Vornberger, P. L. and I. M. Whillans. 1986. Surface features on Ice Stream B, Marie Byrd Land, West Antarctica. Ann. Glaciol., 8, 168-170.

Weertman, J. 1957a. Deformation of floating ice shelves. J. Glaciol., 3(21), 3842.

Weertman, J. 1957b. On the sliding of glaciers. J. Glaciol., 3(21), 33-38.

Weertman, J. 1963. Profile and heat balance at the bottom surface of an ice sheet fringed by mountain ranges. International Association of Scientific Hydrology Publication 61 (General Assembly of Berkeley 1963 Snow and Ice), 245-252.

Weertman, J. 1974. Stability of the junction of an ice sheet and an ice shelf. J. Glaciol., 13(67), 3-11.

Weertman, J. 1976. Glaciology's grand unsolved problem. Nature, 260(5549), 284-286.

Weertman, J. 1986. Basal water and high-pressure basal ice. J. Glaciol., 32(112), 455-463.

Whillans, I. M. 1987. Force budget of ice sheets. In Van der Veen, C. J. and J. Oerlemans, eds. Dynamics of the West Antarctic ice sheet. Dordrecht, etc., D. Reidel Publishing Company, 17-36.

Whillans, I. M. and S. J. Johnsen. 1983. Longitudinal variations in glacial flow: theory and test using data from the Byrd Station strain network, Antarctica. J. Glaciol., 29(101), 78-97.

Whillans, I. M., J. Bolzan and S. Shabtaie. 1987. Velocity of ice streams B and C, Antarctica. J. Geophys. Res., 32(B9), 8895-8902.

The accuracy of the references in the text and in this list is the responsibility of the author, to winom queries should be addressed. 